\title{
Suitability of high-volume aerosol samplers for ultra-trace aerosol iron measurements in pristine air masses: blanks, recoveries and bugs
}

Holly Winton ${ }^{1}$, Andrew Bowie ${ }^{2,3}$, Melita Keywood ${ }^{4}$, Pier van der Merwe ${ }^{2}$, Ross Edwards ${ }^{1}$

$5 \quad{ }^{1}$ Physics and Astronomy, Curtin University, Perth, Western Australia, 6102, Australia

${ }^{2}$ Antarctic Climate and Ecosystems CRC, University of Tasmania, Hobart, Tasmania, 7001, Australia

${ }^{3}$ Institute for Marine and Antarctic Studies, University of Tasmania, Hobart, 7004, Australia

${ }^{4}$ CSIRO Ocean and Atmosphere Flagship, Aspendale, Victoria, 3195, Australia

Correspondence to: V. H. L. Winton (holly.winton@postgrad.curtin.edu.au)

10 Abstract. Atmospheric inputs of soluble iron (Fe) to the global ocean are an important factor determining marine primary productivity and nitrogen fixation. To investigate soluble aerosol Fe and fractional Fe solubility, marine aerosol sampling has been conducted from a number of platforms including aerosol towers, ship and buoy platforms. A number of these studies have used commercially available high-volume aerosol samplers to collect aerosols from large volumes of air. These samplers are attractive for sampling air from low Fe air masses since they can rapidly concentrate large volumes improving

15 detection limits. Here we investigate the use of a high-volume sampler from the Cape Grim Baseline Air Pollution Station (CGBAPS), Tasmania, Australia to sample aerosol Fe from baseline Southern Ocean air-masses. The study followed the United States Environmental Protection Agency (EPA) standard for the sampling of ambient air using high-volume sampler, and the recommendations and protocols from GEOTRACES community for sampling, sample preparation and digestion of trace element aerosols. Analysis and inspection of exposure blank (one month exposure) filters for Fe, and other metals, revealed significant contamination resulting from passive deposition of local soil, plants and insects. The results of the study suggest that high-volume aerosol samplers may not be suitable for low concentration air masses over the Southern Ocean without some mechanism to hermetically seal the sampler when the baseline sampling criteria are not met. 
Atmos. Meas. Tech. Discuss., doi:10.5194/amt-2016-12, 2016

Manuscript under review for journal Atmos. Meas. Tech.

Published: 8 April 2016

(c) Author(s) 2016. CC-BY 3.0 License.
Atmospheric

Measurement

Techniques

Discussions

\section{Introduction}

Aerosols containing iron ( $\mathrm{Fe}$ ) have been investigated over the remote ocean to constrain Fe budgets in surface waters and related biological production. Aerosol sampling for metals such $\mathrm{Fe}$ is particularly challenging in these regions where atmospheric concentrations are exceptionally low. Over the Southern Ocean, atmospheric Fe concentrations are extremely

5 low with reported concentrations less than $60 \mathrm{ng} \mathrm{\textrm {m } ^ { - 2 }}$ of Fe (Bowie et al., 2009; Duce et al., 1991; Gao et al., 2013; Heimburger et al., 2013a; Heimburger et al., 2012; Heimburger et al., 2013b; Prospero, 1996). The low atmospheric concentrations result in low atmospheric fluxes to surface waters. Fertilization experiments in the Southern Ocean have shown that Fe is required for phytoplankton to efficiently undergo photosynthesis and respiration (e.g. Boyd et al., 2007). The Fe-hypothesis (Martin, 1990) has received a lot of interest in the past two decades, whereby the increases in Fe-laden

10 dust, productivity and the degree of nitrate consumption are linked with lowering of atmospheric $\mathrm{CO}_{2}$ during glacial periods (e.g. Lambert et al., 2015; Martínez-García et al., 2014). Primary production may also be co-limited by other transition metals such as manganese (Mn) (Middag et al., 2011), copper (Cu) (Annett et al., 2008), cobalt (Cu) (Saito et al., 2002), zinc (Zn) (Morel et al., 1991) and nickel (Ni) (Price and Morel, 1991).

15 From a biogeochemical perspective, it is not the total amount of Fe supplied to the ocean that is important, but the amount that is bio-available, i.e., the amount available for uptake and utilization by living cells. The most common approach to understanding the delivery of Fe-laden aerosols to phytoplankton has been to quantify the solubility of Fe from aerosols, using Fe leaching experiments. Extremely low soluble aerosol Fe concentrations have been observed in the Southern Ocean, for example 0.07-1.3 $\mathrm{ng} \mathrm{m}^{-3}$ (Gao et al., 2013; Winton et al., 2015). Fractional Fe solubility of mineral dust is typically only

20 1-2 \% of the total Fe content (Baker and Croot, 2010). Ultra-trace metal clean practices and methodologies to limit contamination are required for making reliable measurements of both soluble and total Fe in aerosols from this region. Low blank concentrations from sampling material and during analysis are crucial for reliable measurements (e.g. Bollhöfer et al., 1999; Vallelonga et al., 2002).

25 Very few estimates exist over the Southern Ocean, partly due to the difficulty of sampling clean baseline air. In remote areas, fixed sampling stations rarely exist due to access difficulties or lack of suitable land masses; this covers the majority of the Southern Ocean. Southern Ocean aerosol Fe solubility estimates have resulted from a combination of ship-based and Subantarctic Island land-based aerosol sampling campaigns (e.g. Bowie et al., 2009; Chance et al., 2015; Gao et al., 2013; Wagener et al., 2008). These studies have used wet and dry aerosol deposition samplers “open collector” (Heimburger et al., 30 2012) and Volumetric Flow Controlled (VFC) high-volume aerosol samplers (e.g. Falkland Islands, Pers. Comm. Alex Baker). The recent GEOTRACES 2008 intercalibration experiment (Morton et al., 2013) recommends the use of VFC highvolume aerosol samplers for ship-based marine aerosol sampling. In air masses with low particle loading, high volumes of 
Atmos. Meas. Tech. Discuss., doi:10.5194/amt-2016-12, 2016

Manuscript under review for journal Atmos. Meas. Tech.

Published: 8 April 2016

(c) Author(s) 2016. CC-BY 3.0 License.
Atmospheric

Measurement

Techniques

Discussions

filtered air are required to collect enough material for analysis. To ensure the required mass of sample is collected for analysis, filter substrates are often exposed for long periods of time requiring extra precautions to minimize contamination. Following an international intercalibration experiment between seven laboratories, Morton et al. (2013) recommended Whatman 41 (W41) cellulose fibre filters for low trace element background level applications. This filter substrate can be

5 acid-cleaned to achieve low trace metal blank concentrations (Baker et al., 2006; Morton et al., 2013). Furthermore, W41 filters have a high aerosol particle collection efficiency (e.g. $95 \%$ efficiency for $0.2 \mu \mathrm{m}$ diameter particles (Stafford and Ettinger, 1972), and $99 \%$ for mineral dust (Li-Jones and Prospero, 1998)). Previous aerosol Fe solubility studies that have adopted these protocols and deployed high-volume aerosol samplers both on ships during marine cruises (e.g. Baker et al., 2006; Chance et al., 2015), and on land either at the top of a tower (for example, the clean air site at the Bermuda

10 atmospheric observatory located $50 \mathrm{~m}$ a.s.l. (e.g. Fishwick et al., 2014; Kadko et al., 2015)) or deployed on the rooftop of a building (e.g. Morton et al., 2013).

Most recently, Fe solubility in baseline air over the Southern Ocean has been estimated, using a short time series of archived aerosol filters from Cape Grim Baseline Air Pollution Station (CGBAPS) (Winton et al., 2015). CGBAPS has long been

15 recognized for long-term monitoring of atmospheric species (e.g. Keeling et al., 1996) that are representative of air masses over the remote Southern Ocean. Archived filters from CGBAPS were collected using ultra-trace sampling and methodology previously reported in Bollhöfer et al. (2005). Samplers were deployed at a height of $70 \mathrm{~m}$ at the top of a communications tower at CGBAPS, above the turbulent layer. The Bollhöfer et al. (2005) sampler design prevented local soil contamination as filters were mounted inside a weather shelter i.e., cylindrical filter housing that was sealed pneumatically during non-

20 baseline conditions. In order to extend the short aerosol Fe solubility time series of Winton et al. (2015), we have established an Fe aerosol monitoring program at CGBAPS following GEOTRACES sampling and handling protocols for trace metal analysis (Cutter et al., 2010; Morton et al., 2013) and the United States Environmental Protection Agency (EPA) standard, described by (Chow, 1995), for the sampling of ambient air for total suspended particulates (TSP; all particle sizes) and PM10 (particulate matter diameter $<10 \mu \mathrm{m}$ ) using high volume sampler for the instrument instalment, calibration and

25 operating procedure. The sampling conditions in Winton et al. (2015) cannot be replicated due to new health and safety requirements at the station that prohibit sampling and personal climbing the tower. Therefore, a new method of sample collection was trialled during this study to assess the suitability of VFC high-volume aerosol samplers within the new framework of health and safety regulations. In the present study, a VFC high-volume aerosol sampler was located on the roof deck (90 $\mathrm{m}$ above sea level and $6 \mathrm{~m}$ above the ground) at CGBAPS where other VFC high-volume aerosol collectors

30 are located, which collect samples for PM2.5 and PM10 (particulate matter diameter $<2.5 \mu \mathrm{m}$ and $<10 \mu \mathrm{m}$ respectively) aerosol composition using ion chromatography (Selleck et al., 2014), multi-elemental analysis using accelerator based ion beam analysis (e.g. Cohen et al., 2000) and black carbon using light-absorbing techniques (Cohen and Stelcer, 2014). 
Atmos. Meas. Tech. Discuss., doi:10.5194/amt-2016-12, 2016

Manuscript under review for journal Atmos. Meas. Tech.

Published: 8 April 2016

(c) Author(s) 2016. CC-BY 3.0 License.

(c) (i)

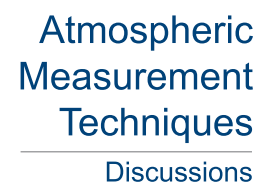

As the first step in developing a reliable multi-year Fe time series at the site we investigated a series of filter blanks and baseline aerosol samples. The samples were collected using the EPA standard and GEOTRACES recommended procedures and a VFC high-volume sampler. A combination of Fe leaching experiments, total aerosol digestions, optical light microscopy, scanning electron microscopy (SEM) and enrichment factor analysis were used to assess the reliability of the aerosol samples for Fe solubility studies in baseline Southern Ocean air.

\section{Methods}

\subsection{Study site and aerosol collection}

\subsubsection{Site details}

Cape Grim Baseline Air Pollution Station (40.68 S, 144.69 E) monitors long-term changes in a range of atmospheric species,

10 including greenhouse gases, aerosols, and meteorological parameters. Monitoring occurs during baseline conditions i.e., when the wind direction is between $190^{\circ}$ and $280^{\circ}$ (Fig. 1a) and the total aerosol particle counts are below a threshold concentration based on the $90^{\text {th }}$ percentile of hourly medians for the previous five years. These conditions occur $\sim 30 \%$ of the time (Keywood, 2007) and are representative of air masses over the remote Southern Ocean.

\subsubsection{Aerosol sampler setup}

15 Aerosols were sampled using a VFC high-volume aerosol collector (Lear-Siegler) located on the roof deck at CGBAPS (Fig. 1). We followed the United States EPA standard, described by (Chow, 1995), for the sampling of ambient air for TSP and PM10 using high volume sampler for the instrument instalment, calibration and operating procedure. The sampler was mounted against the northwest side of the roof deck wall. Prevailing winds at the site are from the southwest. Sampling airflow through the collector was automatically triggered during baseline conditions. At the onset of the project the collector

20 was setup to collect TSP. However, optical light microscope inspection of the filters revealed large particles, up to $100 \mu \mathrm{m}$ in diameter, (see Sect. 3.1.). Microscope images of the particles suggested that they were derived from local soil. Similar soil contamination of CGBAPS filters has been previously reported (Ayers, 2001). To reduce soil contamination a size-selective inlet was installed (PM10) on the sampler partway through the project (Fig. 1).

\subsection{Laboratory environment, labware and reagents}

\section{2.2.1 Laboratory environment}

All cleaning of labware, filters and sample preparation and analysis was conducted in the Curtin University TRACE facility. The TRACE facility is a large multi-stage clean room designed for ultra-trace metal measurements. 
Atmos. Meas. Tech. Discuss., doi:10.5194/amt-2016-12, 2016

Manuscript under review for journal Atmos. Meas. Tech.

Published: 8 April 2016

(c) Author(s) 2016. CC-BY 3.0 License.

(c) (i)

\author{
Atmospheric \\ Measurement \\ Techniques \\ Discussions
}

\subsubsection{Reagents}

All the apparatus that came in contact with the aerosol filters was acid cleaned following GEOTRACES protocols (Cutter et al., 2010). Nitric acid $\left(\mathrm{HNO}_{3}\right)$ and hydrochloric acid ( $\left.\mathrm{HCl}\right)$ used throughout the study was high purity ( $<10$ ppt or $0.2 \mathrm{nmol}$ $\mathrm{L}^{-1} \mathrm{Fe}$ ). Both acids were double distilled in-house from Seastar ${ }^{\circledR}$ Instrument Quality (IQ) grade acids (Choice Analytical Pty 5 Ltd, Australia) using an all polytetrafluoroethylene (PFA) acid purification system (DST-1000, Savillex®). Hereafter referred to as ultra-pure acid. This acid was used for both cleaning of labware and filters and for sample and standard preparation. Seastar Baseline ${ }^{\circledR}$ grade hydrofluoric acid (HF) and $\mathrm{HNO}_{3}$ (Choice Analytical Pty Ltd, Australia) was used in the digestion of aerosol filters. Ultra-pure water (resistivity of $18.2 \mathrm{M} \Omega$-cm, Purelab Classic, ELGA, Germany) was used throughout.

\subsubsection{Labware preparation}

Low-density polyethylene bottles (LDPE; Nalgene) and polypropylene (PP; Elemental Scientific Inc.) vials were rigorously acid-washed using the following procedure:

1. One week immersion in $3.2 \mathrm{~mol} \mathrm{~L}^{-1}$ IQ grade $\mathrm{HNO}_{3}$. All labware was rinsed with copious quantities of ultra-pure water between acid baths;

15

2. One week in $1.2 \mathrm{~mol} \mathrm{~L}^{-1}$ ultra-pure $\mathrm{HCl}$;

3. One week in $0.12 \mathrm{~mol} \mathrm{~L}^{-1}$ ultra-pure $\mathrm{HCl}$;

4. One week in $0.16 \mathrm{~mol} \mathrm{~L}^{-1}$ ultra-pure $\mathrm{HNO}_{3}$; and

5. One week in ultra-pure water.

Teflon filtration parts used in leaching experiments were cleaned in a series of acid baths on a hotplate at $80{ }^{\circ} \mathrm{C}$ for three days. The first bath consisted of $7.9 \mathrm{~mol} \mathrm{~L}^{-1}$ ultra-pure $\mathrm{HNO}_{3}$, followed by $5.8 \mathrm{~mol} \mathrm{~L}^{-1}$ ultra-pure $\mathrm{HCl}$, then $0.12 \mathrm{~mol} \mathrm{~L}^{-1}$ ultra-pure $\mathrm{HCl}$ and $0.16 \mathrm{~mol} \mathrm{~L}{ }^{-1}$ ultra-pure $\mathrm{HNO}_{3}$, and finally ultra-pure water. Filtration parts were rinsed with copious quantities of ultra-pure water between baths.

\subsubsection{Filter preparation}

Aerosol collection substrates were all W41 paper sheets (20 x $25 \mathrm{~cm}$; Whatman) acid-washed before use following the method of Baker et al. (2006) and GEOTRACES recommendations (Morton et al., 2013). Briefly, W41 filter sheets were arranged in layers, one at a time, between polypropylene (PP) mesh, in a series of three $0.5 \mathrm{~mol} \mathrm{~L}^{-1}$ ultra-pure $\mathrm{HCl}$ baths for 24 hours. Filters were then rinsed three times with ultra-pure water between baths and then placed in a fresh acid bath. Plastic ziplock bags and plastic tweezers were acid-washed using $3 \%\left(0.5 \mathrm{~mol} \mathrm{~L}^{-1}\right)$ ultra-pure $\mathrm{HNO}_{3}$ for 2 weeks. Acidwashed filters were stored in individual acid-washed ziplock bags until use. 
Atmos. Meas. Tech. Discuss., doi:10.5194/amt-2016-12, 2016

Manuscript under review for journal Atmos. Meas. Tech.

Published: 8 April 2016

(c) Author(s) 2016. CC-BY 3.0 License.

(c) (i)

$\begin{array}{r}\text { Atmospheric } \\ \text { Measurement } \\ \text { Techniques } \\ \hline \text { Discussions }\end{array}$

\subsection{Sampling procedures and quality control}

\subsubsection{Filter changing procedure}

Loading and changing of aerosol collection substrates was carried out under a laminar flow clean bench at CGBAPS, and aerosol-laden filters were transferred into individual pre-acid-washed ziplock plastic bags immediately after collection and

5 stored frozen until analysis.

\subsubsection{Filter blanks and aerosol samples}

Four types of filter blanks were analysed during the study: (i) untreated filter laboratory blanks, (ii) acid-washed filter laboratory blank, (iii) procedural filter blanks, and (iv) one-month exposure filter blanks. Procedural blanks consisted of acid-washed filters mounted in the aerosol collector for five minutes, with the air pump off. The one-month exposure blank,

10 was collected by the same method as the procedural blank, but for one month duration. The exposure blank was carried out after the PM10 inlet was installed on the collector. Monthly aerosol sampling (TSP) began in June 2013 and the PM10 size selective inlet was installed in November 2013. Actual samples used for optical and Scanning Electron Microscopy (SEM) observations were CG13TM01 (TSP; sampled between 13 June 2013 and 16 July 2013) and CG13TM08 (PM10; sampled between 28 January 2014 and 25 February 2014). Sampling dates and volumes for blank filters and aerosol samples used in

15 this study are reported in Table 1.

\subsubsection{Certified Reference Materials and quality control filters}

A certified reference material and a commercial quality control spiked filter were used to validate sample digestion procedures. These included the MESS-3 marine sediment (National Research Council, Canada) and a trace metal spiked quality control nitrocellulose filter (QC-TMFM-A, High Purity Standards).

\section{$20 \quad$ 2.3.4 Sample preparation}

Soluble metals were extracted from each type of blank filter. Circular portions (47 mm diameter) were cut out of the blank filter sheets using a punch cutter (designed at Curtin University), which consisted of a sharpened titanium (Ti) circular blade and a PFA backing mount (both acid-washed). Soluble metals including aluminium (Al), Ti, Manganese (Mn), Fe, and lead $\mathrm{Pb})$ were extracted from the filter using an instantaneous flow-through water leach (e.g. Aguilar-Islas et al., 2010)

25 consisting of three separate passes of $10 \mathrm{~mL}$ of ultra-pure water. Three aliquots of each filter blank were leached with three repeated passes of ultra-pure water.

Total trace metal concentrations were determined following recommendations from the 2008 GEOTRACES intercalibration experiment for the analysis of marine aerosols (Morton et al., 2013). All digestions were carried out under high-efficiency 30 particulate arresting (HEPA) filtered air, in a total-exhausting clean-air (ISO Class 5), hot block unit (SCP Science, Canada) 
Atmos. Meas. Tech. Discuss., doi:10.5194/amt-2016-12, 2016

Manuscript under review for journal Atmos. Meas. Tech.

Published: 8 April 2016

(c) Author(s) 2016. CC-BY 3.0 License.
Atmospheric

Measurement

Techniques

Discussions

fitted with an acid scrubber unit at the University of Tasmania. Circle portions (47 mm) of the filters were digested at $95{ }^{\circ} \mathrm{C}$ for 12 hours with concentrated ultra-pure $\mathrm{HNO}_{3}\left(1 \mathrm{~mL}\right.$, Seastar Baseline $\left.{ }^{\circledR}\right)$ and ultra-pure $\mathrm{HF}\left(0.25 \mathrm{~mL}\right.$, Seastar Baseline $\left.{ }^{\circledR}\right)$ in capped PFA vials (15 mL, acid cleaned Savillex ${ }^{\circledR}$ ) following Bowie et al. (2010). At the end of the digestion, the samples were evaporated to dryness, reconstituted in $10 \%\left(1.60 \mathrm{~mol} \mathrm{~L}^{-1}\right)$ ultra-pure $\mathrm{HNO}_{3}\left(10 \mathrm{~mL}\right.$ final volume, Seastar ${ }^{\circledR}$ IQ grade double distilled in-house) and stored at $40{ }^{\circ} \mathrm{C}$ for $\sim 48$ hours before analysis. Two certified reference materials (MESS-3 marine sediment, National Research Council, Canada, and QC-TMFM-A spiked trace metals on nitrocellulose filter (TMF), High Purity Standards) were digested alongside the samples to test the digestion recovery procedure. Total digestion recovery for Fe from the MESS-3 CRM was $108 \pm 8 \%(n=3)$ and TFM was $99 \pm 7 \%(n=3)$. Recovery rates for other trace metals are reported in Supplementary Table 1. Blank concentrations for Savillex ${ }^{\circledR}$ beakers, i.e. the digestion blank, are reported in Table 2.

\subsection{High-resolution inductively coupled plasma mass spectrometry analysis}

Leachates and resuspended total digests were analysed using high-resolution inductively coupled plasma mass spectrometry (HR-ICP-MS, Element XR ThermoFisher). An auto sampler fitted with an acrylic sample enclosure was used to introduce the sample to the HR-ICP-MS. Measured isotopes and spectral resolutions, along with typical operating conditions, are

15 reported in Supplementary Table 2. The HR-ICP-MS was operated with a jet interface using Ni jet and sample cones and an Apex desolvation unit (Elemental Scientific Inc, ESI) pumped with a Seafast II system syringe pumps (ESI). Samples were analysed in groups of ten bracketed by instrumental blanks ( $3 \%$ or $0.4 \mathrm{~mol} \mathrm{~L}^{-1}$ ultra-pure $\mathrm{HCl}$ (soluble) or $\mathrm{HNO}_{3}$ (total)), and a quality control standard (QC). The QC standard was prepared from a commercial mixed elemental standard (Cat. \#ICP200.7-6 Solution A, High Purity Standards) by serial dilution. Partial procedural blanks were also determined. These

20 included blanks for the leaching and total digestion procedures. Leaching and total digestion blanks consisted of ultra-pure water processed identically to filter leachates and total digestion samples. All samples and standards were prepared on a similar matrix basis. Leachates were acidified to $1 \%\left(0.12 \mathrm{~mol} \mathrm{~L}^{-1}\right) \mathrm{HCl}$, and total digests were diluted and presented to the instrument as $3 \%\left(0.5 \mathrm{~mol} \mathrm{~L}^{-1}\right) \mathrm{HNO}_{3}$. The sample introduction line was rinsed with $3 \%\left(0.4 \mathrm{~mol} \mathrm{~L}^{-1}\right)$ ultra-pure $\mathrm{HCl}(3 \%$ or $0.5 \mathrm{~mol} \mathrm{~L}-1$ ultra-pure $\mathrm{HNO}_{3}$ ) between leachate (digest) samples for 1.5 minutes. Standard solutions were prepared by

25 serial dilution from $100 \mu \mathrm{g} \mathrm{mL} \mathrm{m}^{-1}$ stock solutions using ultra-pure water, with a final $\mathrm{HCl}\left(\mathrm{HNO}_{3}\right)$ concentration of $1 \%$ or $0.12 \mathrm{~mol} \mathrm{~L}^{-1}$ (3 \% or $0.5 \mathrm{~mol} \mathrm{~L}^{-1}$ ). Preparation of standards in $1 \%$ or $0.12 \mathrm{~mol} \mathrm{~L}^{-1}$ ultra-pure $\mathrm{HCl}$ (3\% or $0.5 \mathrm{~mol} \mathrm{~L}^{-1}$ ultrapure $\mathrm{HNO}_{3}$ ) matrix matched the leachates (digests). Ten-point calibration solutions were measured. Indium (In), at a concentration of $1.5 \mathrm{ppb}$, was used as an internal standard.

\subsection{Optical and Scanning Electron Microscopy}

30 Blank filters (acid-washed laboratory, procedural, and exposure) were examined using optical microscopy to investigate particulate contamination (morphology and particle size). Actual aerosol samples with visible contamination under the optical microscope were further investigated using a SEM (Zeiss Evo 40XVP and Zeiss Neon 40EsB FIBSEM). The SEM 
Atmos. Meas. Tech. Discuss., doi:10.5194/amt-2016-12, 2016

Manuscript under review for journal Atmos. Meas. Tech.

Published: 8 April 2016

(c) Author(s) 2016. CC-BY 3.0 License.

(c) (i)

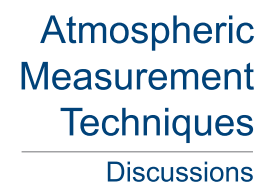

was fitted with secondary (SE) and backscatter (BSD) electron detectors and a SiLi energy dispersive X-ray system (EDS) with Oxford Inca software were used to give a qualitative indication of the geochemistry of the particles. The conditions used ( $\mathrm{kV}$, spot size, WD and detector) are shown on the SEM images. Filter blanks were carbon-coated prior to SEM examination.

\section{2.6. Air mass back trajectory analysis}

Air mass back trajectories were simulated using ANSTO's air mass back trajectory database, based on the NOAA's HYSPLIT v4.0 model (Draxler and Rolph, 2003) for the duration of the one-month exposure blank. Five-day air mass back trajectories were generated for the CGBAPS, based on a starting elevation of $200 \mathrm{~m}$ a.g.l., for every hour of every day between 8 November and 10 December 2013. Hindcasts were based on meteorological data of $0.5^{\circ} \times 0.5^{\circ}$ resolution

10 generated by the global data assimilation system (GDAS) model downloaded from the NOAA ARL website (ftp://arlftp.arlhq.noaa.gov/archives/gdas0p5).

\section{Results}

\subsection{Optical and Scanning Electron microscopy}

Filter blanks and baseline sample filters were inspected by a combination of optical microscopy and SEM. Inspection of

15 acid-washed laboratory and procedural blank filters with an optical microscope showed no obvious sign of particulate contamination. In contrast, the one-month exposure blank and aerosol samples from the aerosol collector (using both the TSP and PM10 inlets) were contaminated with particles up to $100 \mu \mathrm{m}$ in diameter (Fig. 2-4). Visibly discoloured (orange) patches were also observed on a number of baseline TSP and PM10 filter samples (Fig. 3b). No discoloured patches were found on the blank filters. Baseline sample filters (both TSP and PM10) were inspected using a SEM. Particles were

20 comprised of salt ( $\mathrm{NaCl}$, cubical crystals), gypsum, calcium carbonate, mineral dust (identified by the silicon ( $\mathrm{Si}$ ), $\mathrm{Fe}, \mathrm{Al}, \mathrm{Ti}$ EDS signals), and silica was identified on the PM10 filters (Fig. 5). The TSP filters were coated with a broader variety of material compared to the PM10 filters. Particles on the TSP filter were identified as carbonaceous particles, salts, mineral dust, silica sand, spores, and marine aerosol (particles containing magnesium (Mg), strontium (Sr) and barium (Ba); Fig. 6).

\subsection{Solubility of contamination-borne particles on blank filters}

25 A typical volume of baseline air collected during a month deployment (ca. $12600 \mathrm{~m}^{3}$, assuming baseline conditions occur for $30 \%$ of the time (Keywood, 2007)) was used to calculate filter blank concentrations for aerosol samples, and compare them to the aerosol concentrations on a "per cubic meter of air" basis (Morton et al., 2013). Leaching Fe from the blank filters with the use of ultra-pure water gave soluble Fe concentrations for the four types of blank filters, which can be used as a basis for comparison to other studies. The average soluble trace metal concentrations for the three subsamples of each type of filter are reported in Table 3 and Fig. 7. Soluble trace metal concentrations in all blank filters decreased with each 
Atmos. Meas. Tech. Discuss., doi:10.5194/amt-2016-12, 2016

Manuscript under review for journal Atmos. Meas. Tech.

Published: 8 April 2016

(c) Author(s) 2016. CC-BY 3.0 License.

(c) (i)

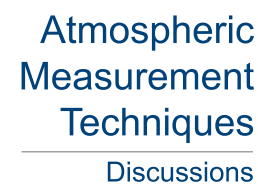

additional sequential leach of ultra-pure water (Fig. 7). At least $50 \%$ of soluble trace metals were leached within the first leach i.e., $\sim 65 \%$ of soluble $\mathrm{Fe}, \sim 55 \%$ of soluble $\mathrm{Al}, \sim 70 \%$ of soluble $\mathrm{Ti}, \sim 65 \%$ of soluble $\mathrm{V}, \sim 75 \%$ of soluble $\mathrm{Mn}$, and $\sim 60 \%$ of soluble $\mathrm{Pb}$ for the exposure blank filter.

5 After acid-cleaning the filters, there was a significant decrease in the concentration of soluble Fe, from 200 to $30 \mathrm{pg} \mathrm{cm}^{-2}$. Acid-cleaning the filters also reduced the concentrations of soluble $\mathrm{Mn}, \mathrm{Pb}$, and $\mathrm{Ti}$ in the leachates, but there was no difference in the soluble V concentrations between acid-washed and untreated filters (Fig. 7). Soluble Al was the only trace metal to increase in concentration (12 to $2600 \mathrm{pg} \mathrm{cm}^{-2}$ ) after acid-washing the filter; perhaps, due to Al contained within the cellulose filter and further broken down by $\mathrm{HCl}$.

10

For the procedural blank filters, i.e., those taken to the field and mounted in the VFC high-volume aerosol sampler for five minutes (Table 3), the soluble Fe concentrations (16 $\mathrm{pg} \mathrm{cm}^{-2}$ of soluble Fe) were similar to the blank acid-washed filters (30 pg $\mathrm{cm}^{-2}$ of soluble $\mathrm{Fe}$ ). This validates the cleanliness of our sample handling procedures. Soluble $\mathrm{Ti}, \mathrm{V}, \mathrm{Mn}, \mathrm{and} \mathrm{Pb}$ concentrations between acid-washed filter blanks and procedural blanks were also similar. Soluble $\mathrm{Al}$ was lower in the 15 procedural blank.

In the month-long exposure blank, a considerable increase in the trace metal concentration was observed; for example, up to $870 \mathrm{pg} \mathrm{cm}^{-2}$ of soluble Fe. The concentration of all soluble trace metals was at least an order of magnitude greater in the exposure blank than in the procedural and acid-washed filter blank. Soluble Al displayed the highest concentrations in laboratory, procedure, and exposure blank filters.

\subsection{Total trace metal concentrations of contamination-borne particles on blank filters}

Similar to the soluble trace metal concentrations, acid-cleaning the filters significantly decreased in the total concentration of all trace metals, except for $\mathrm{V}$ where the concentration remained the same (Table 2). Procedural blank concentrations were slightly higher than the acid-washed filters for total $\mathrm{Al}$, total $\mathrm{Ti}$, total $\mathrm{V}$, and total $\mathrm{Pb}$ concentrations. The procedural blank total Fe concentration was $\sim 7 \mathrm{pg} \mathrm{cm}^{-2}$ lower than the acid-washed filter. Exposure blank total trace metal concentrations were an order of magnitude higher than procedural blank concentrations for all trace metals.

\section{Discussion}

\subsection{Contamination from laboratory procedures, filter handling and site exposure}

We used a series of blank filter types to determine the source and quantity of soluble and total Fe contamination. The blank

30 Fe budget consists of Fe introduced to the sample from reagents, ultra-pure water, leaching from plastic bottles and filter substrate, sample collection and handling, and the instrument (Table 4). The instrumental water blank gives an indication of 
Atmos. Meas. Tech. Discuss., doi:10.5194/amt-2016-12, 2016

Manuscript under review for journal Atmos. Meas. Tech.

Published: 8 April 2016

(c) Author(s) 2016. CC-BY 3.0 License.

(c) (i)

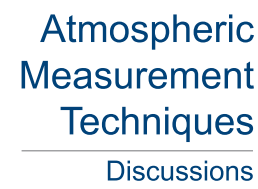

contamination arising from the HR-ICP-MS vial, ultra-pure acids and the instrument. This contribution is $\sim 0.4 \mathrm{pg} \mathrm{cm}^{-2}$. Contamination from the W41 filter substrate is assessed by the difference in Fe between acid-washed and untreated filters. The W41 filters contributes $0.2 \mathrm{ng} \mathrm{cm}^{-2}\left(9 \mathrm{pg} \mathrm{m}^{-3}\right)$ of soluble Fe and $7 \mathrm{ng} \mathrm{cm}^{-2}\left(0.3 \mathrm{ng} \mathrm{m}^{-3}\right)$ of total Fe to the Fe budget. Thus, acid-washing the filter is crucial for baseline aerosol sampling. Acid-washing of the W41 filters is also necessary when

5 analysing the trace solubility of $\mathrm{Mn}, \mathrm{Pb}$, and $\mathrm{Ti}$ as acid-washing significantly reduced the contamination arising from the filter substrate alone.

The Fe concentrations of the procedural blanks indicate the contamination acquired throughout the sampling process and handling of filters in the field. The sampling procedure contributes negligible total and soluble Fe to the budget (Table 4). By

10 following ultra-trace protocols (GEOTRACES recommendations), contamination by personal or handling of filters was minimised; blank concentrations in acid-washed laboratory blank filters are similar to or less than procedural blank filters. Furthermore, no evidence of particulate contamination was observed in the acid-washed or procedural blank filters under an optical microscope.

15 There is considerable contamination derived from filter exposure at the sampling site. The largest source of soluble Fe contamination was evident in the month-long exposure blank. Contamination arising from one-month of site exposure is around $0.03 \mathrm{ng} \mathrm{m}^{-3}$ of soluble Fe and $10 \mathrm{ng} \mathrm{m}^{-3}$ of total Fe. This is considerable given water soluble Fe concentrations in contamination-free archived filters ranged from 0.01-0.3 $\mathrm{ng} \mathrm{m}^{-3}$ of soluble Fe and 0.04-5.8 $\mathrm{ng} \mathrm{m}^{-3}$ of total Fe (Winton et al., 2015). The contamination-free archived filters were sampled using the Bollhöfer et al. (2005) aerosol sampler design (Fig.

20 S1) and a similar Fe water solubility leaching scheme employed here. Thus, in the low concentration aerosol samples, contamination from site exposure (Tables 2 and 3) limits our ability to differentiate between the blank and 'real' signal. We suggest two processes by which contamination occurs during the month-long exposure. Firstly, by a passive deposition on the filters during a month-long sampling period at Cape Grim. Passive deposition contributes the majority (94 \%) of Fe to the Fe budget (Table 4). Secondly, as there is no evidence of human-, sampler-, or building-derived (e.g., wood, paint)

25 particles on the filters, the insect, soil, and marine particle contamination is likely a consequence of airborne particles hitting the sampler at high wind speeds. Additionally, insects could fly or crawl into to sampler, as the air inlet is not sealed during non-baseline conditions (Fig. 1). Insect contamination is likely at other sampling sites as indicated by the sampling procedure in the US EPA high-volume sampling standard for the determination of inorganic compounds in ambient air, which recommends that insects be removed with a pair of tweezers.

The total trace metal blank concentrations in acid-washed and untreated W41 filters are similar to those reported by Morton et al. (2013), who use the same acid-washing procedure for cleaning the filters. It is interesting to note that Morton et al. (2013) reports a greater Al concentration on the acid-washed filter than the untreated filter. Our soluble Al blank 
Atmos. Meas. Tech. Discuss., doi:10.5194/amt-2016-12, 2016

Manuscript under review for journal Atmos. Meas. Tech.

Published: 8 April 2016

(c) Author(s) 2016. CC-BY 3.0 License.

(c) (i)

Atmospheric

Measurement

Techniques

Discussions

concentrations were also greater for the acid-washed filter Al suggesting the W41 filters are not suitable for Al studies in Southern Ocean baseline air.

\subsection{Passive deposition and back trajectory analysis}

The exposure blank, which was left in the aerosol collector with the motor switched off for a one-month collection period,

5 reflects contamination derived from the atmospheric fallout or passive deposition. This type of blank gives an indication of the relative magnitudes of the in-sector active sampling (i.e., pump turned on and controlled by the baseline switch for a month) versus passive deposition. The deposition of particles, is thus, partly dependent on the mixture of in- and out-sector winds during the exposure blank period. The cluster means of five-day air mass back trajectories, for the duration of the month-long exposure blank, show that around half of the trajectories were transported from the non-baseline sector (i.e., over

10 Tasmania) while the other half were baseline marine air (Fig. 7b). The frequency plot in Fig. 7c shows the fetch area of trajectories, which included Tasmania $>10 \%$ of the time, and occasionally, the Australian continent (>0.1 \%) (Fig. 7b). Furthermore, the high wind speeds at Cape Grim, up $80 \mathrm{~km} \mathrm{~h}^{-1}$ during the exposure blank period (Fig. 7a), potentially transport local dust and vegetation to the sampling site. The wind speed is most important when the sampler is turned off (i.e., non-baseline conditions) as it can transport and deposit local dust and insects through the unsealed air inlet section of

15 the sampler (visible in Fig. 1d). Extreme weather conditions at this site are a concern for aerosol samplers that are not sealed during non-baseline conditions; contamination occurs regardless of whether the sampler is turned on or off. The Bollhöfer et al. (2005) sampler design minimized this source of contamination by pneumatically sealing the sampling when it was turned off.

20 We use optical microscopy to further assess the impact of passive deposition. Large particles up to $100 \mu \mathrm{m}$ are observed in the exposure blank (Fig. 2). A mixture of mineral dust, vegetation, and even insects were observed on the exposure blank (Fig. 2). Large particles were still observed on filters after the installation of the PM10 size selective inlet (Fig. 4). An evaluation of PM10 size selective inlet performance in Australia found that PM10 inlets have a $d_{50}$ of $10 \mu \mathrm{m}$, i.e., $50 \%$ of particles greater than $10 \mu \mathrm{m}$ are collected on the inlet (Keywood, 1999). The calibration of the PM10 inlet collection

25 efficiencies is done under certain wind speed conditions and it is likely that the extreme wind speeds at Cape Grim $\left(80 \mathrm{~km} \mathrm{~h}^{-}\right.$ 1; Fig 8c) are higher than what the inlet was calibrated in. This may explain why some particles larger than $10 \mu \mathrm{m}$ are observed on the PM10 sample filter (Fig. 4). These particles could have been deposited on the filter by a combination of high wind speeds when the sampler was running, which lowered the efficiency of PM10 inlet to separate particles $<10 \mu \mathrm{m}$, and/or passive deposition when the sampler was turned off. Given the large particle size and the wind strength of non-baseline air

30 (Fig. 7), the source of passive deposition is likely local.

Local contamination from the cliff face at Cape Grim has been known to occur for some time (Ayers, 2001), and elemental ratios are used to correct for this local cliff contamination for major ion measurements (Ayers and Ivey, 1988). Due to the 
Atmos. Meas. Tech. Discuss., doi:10.5194/amt-2016-12, 2016

Manuscript under review for journal Atmos. Meas. Tech.

Published: 8 April 2016

(c) Author(s) 2016. CC-BY 3.0 License.
Atmospheric

Measurement

Techniques

Discussions

very weak signal at Cape Grim, fingerprinting (e.g. using elemental ratios or radiogenic isotope ratios) the cliff signal and separating it from the marine particles is challenging. As there is a clear indication of material from the cliff face being blown onto the roof deck during extreme wind events, the soil signal is likely to dominate the marine signal for trace metals. The high concentration of soluble Fe in the exposure blank, sampled at the roof deck height, is as high or higher than soluble

5 Fe in uncontaminated samples collected up the $70 \mathrm{~m}$ communications tower (Bollhöfer et al. (2005) sampler design; (Winton et al., 2015). This local contamination will likely mask or dominate the true Fe solubility of baseline aerosols. At Cape Grim, there is no option to install the sampler elsewhere, e.g. higher up on a tower as has been done in the past (Bollhöfer et al., 2005). Using an impactor - for example, with a maximum of six upper stages and a backup filter - may aid in the identification of contamination if the size distribution of the marine aerosol and the cliff debris were known and if those size

10 distributions were significantly different. However, this is likely to result in detection problems of soluble trace metals since the aerosol would be deposited and spread across seven filters instead of one. To overcome this, a PM10 size selective head was installed at Cape Grim to remove the coarse particle size distribution that is not long-range or baseline transport. Cohen and Stelcer (2014) suggested that for non-baseline PM 2.5 samples, windblown soil (estimated from the oxides of Al, Si, Ti, $\mathrm{Ca}$, and $\mathrm{Fe}$ ) represents about $2 \%$ of the total fine mass at Cape Grim. The remaining fine particle mass comprises sea salt

15 (38\%), black carbon (4\%), and organic matter (5\%). Even if windblown soil only contributes $2 \%$ of the total fine aerosol mass in samples, this could be a large fraction of the trace metal component due to their abundance in the soil particles (Taylor and McLennan, 1985) and significantly affect solubility. The passive deposition of locally-derived particles during out-sector winds will thus have a major influence on the overall aerosol Fe solubility in baseline samples.

20 The issue of local contamination has also been identified on Kerguelen Island, located in the Indian sector of the Southern Ocean during an aerosol sampling campaign. Using Al/Ti ratios as a tracer of local soil erosion, Heimburger et al. (2013a) found that out of 14 rain samples, only five were free of local contamination and representative of long-range transport particles deposited by rain events. The sampling location has been shown to be a major factor when designing trace metal studies in the Southern Ocean. Other Sub-Antarctic Island sites will likely face similar issues of local contamination such as

25 at Cape Grim and Kerguelen Island. Thus, there is a need for future aerosol campaigns of baseline trace metal solubility to sample aerosols high above the turbulent layer, for example, Cape Verde (30 m) (e.g. Fomba et al., 2012) and Tudor Hill, Bermuda (23 m) (e.g. Fishwick et al., 2014; Kadko et al., 2015).

\subsection{Enrichment factor analysis}

The Wedepohl (1995) compilation of continental crust composition was used to calculate crustal enrichment factors (EF) to

30 determine the contribution of mineral dust to the observed total elemental concentrations in the blank filters. Total Al was used as a marker for mineral dust. For an element (Z) in a sample, the EF relative to $\mathrm{Al}$ is calculated using Eq. (1).

$E F=\frac{(Z / A l)_{\text {sample }}}{(Z / A l)_{\text {crust }}}$ 
Atmos. Meas. Tech. Discuss., doi:10.5194/amt-2016-12, 2016

Manuscript under review for journal Atmos. Meas. Tech.

Published: 8 April 2016

(c) Author(s) 2016. CC-BY 3.0 License.

(c) (i)

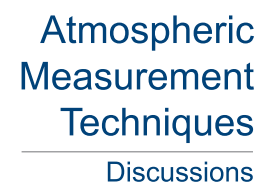

The enrichment factors of exposure blank filters are used to gauge the level of mineral dust contamination from a month of exposure at the field site. For example, an EF between 0.7 and 2 is considered to be similar to the upper continental crust, implying that these trace metals might have originated from that source. Trace metals had EF between 1.5 - 4.8 (Table 5); this is considered as a similar composition or moderate enrichment, in comparison to the upper continental crust (i.e. EF

5 >0.7). Total Fe does not show Fe enrichment, suggesting that anthropogenic Fe was not a source of contamination to the exposure blank, although it is known to be a source of atmospheric soluble Fe (e.g. Sholkovitz et al., 2012). The low EF values of all trace metals suggest that the trace metals on the exposure blank could have originated from mineral dust sources. The low EFs of all trace metals in the month-long exposure blank that was subject to passive deposition and air masses crossing Tasmania (Fig. 7) are likely to reflect local contamination from crustal sources e.g. mineral dust from the cliff face.

\subsection{Recommendations and future work}

\subsubsection{Importance of microscope observations in trace metal aerosol collection}

The main concern when collecting marine-derived trace metal aerosol particles at CGBAPS is that the filters also collect dust from the local cliff-face directly below the sampler at the station, particularly during stormy conditions. The filters are also

15 subject to passive deposition while the wind is out of baseline sector, which is significant because of the already weak signal at CGBAPS. Therefore, microscope observations are a key tool in the identification of local contamination. We recommend that microscope observation becomes a routine practice when measuring the Fe content and solubility in aerosols from the Southern Ocean. For example, insect and vegetation contamination was found in our blank filters only through the use of microscope observations, and this source of contamination would not have been detected by the soluble geochemistry alone.

\subsubsection{Bioactivity inside filters}

Sporadic discolorations (orange spots) were identified on the PM10, TSP, and month-long exposure blanks. Microscope observations showed that these spots were located inside the 'depth' of the filter (Fig. 3b). A possible source for these spots is microbial growth inside the filters. Algae could be living off nutrients e.g. aerosol nitrate in the aerosol-laden filter. Microbes will also accumulate trace metals (Morel and Price, 2003) and affect the solubility. Further work is required to assess these orange spots and determine whether they are an additional source of trace metal contamination.

\subsubsection{Aerosol sampler siting and closure requirements for low iron air sampling}

Much of the passive deposition contamination found by this study was invisible to the naked eye. However, it was still a significant source of the Fe blank budget compared to the expected Fe aerosol loading. In the case of this study, the sampler was on a platform $\sim 6 \mathrm{~m}$ above the ground and exposed to extreme wind conditions. The contamination was primarily due to the lack of an air-tight closure at the sampler intake. As a result, strong winds were able to force particles into the sampler 
Atmos. Meas. Tech. Discuss., doi:10.5194/amt-2016-12, 2016

Manuscript under review for journal Atmos. Meas. Tech.

Published: 8 April 2016

(c) Author(s) 2016. CC-BY 3.0 License.

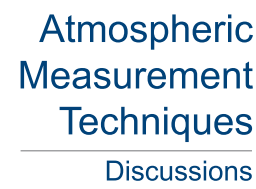

(c) (i)

and onto the filter. This form of contamination may be decreased by installing the sampler above the surface boundary layer ( $\sim 50 \mathrm{~m}$ ); however a hermetic closure is still desirable to keep out air that is out of sector (e.g. Bollhöfer et al., 2005; Winton et al., 2015) (Fig. S1). Due to new work health and safety requirements imposed on the field station, it is not possible to carry out a comparison of sampling on the $70 \mathrm{~m}$ tower and roof deck to determine if sampling above the turbulent layer

5 decreases contamination. Ship based high-volume samplers are exposed to particulates from ship exhaust (Edwards, 1999). For similar reasons they should be fitted with a hermetic closure to completely seal off the sampler when the winds are out of sector or the wind speed is too low. For example, Edwards (1999) investigated ship-derived contamination along an upwind/downwind transect of snow on Antarctic sea ice. In contrast to the low upwind iron concentrations, downwind concentrations were up to two orders of magnitude higher than the upwind samples, suggesting that snow is significantly contaminated by material carried in the air from the ship.

\section{Conclusion}

A VFC high-volume aerosol sampler was installed at CGBAPS under new health and safety regulations, and following ultratrace protocols and recommendations of the US EAP standard and GEOTRACES community for aerosol sampling. Using a series of blank filter types, we assessed the contribution of Fe contamination during different stages in the sampling, leaching

15 and analysis of baseline Fe solubility at CGBAPS. To do this we used a combination of solubility experiments, microscope observations, and enrichment factor analysis of one-month exposure blank filters. Contamination arising from HR-ICP-MS, lab wear and handling of filters was negligible. Acid-washing the filters substantially reduced Fe leached from the W41 filter substrate. The most significant source of contamination was the passive deposition during aerosol sampling while the wind was out of the baseline sector. This source of contamination cannot be seen with the naked eye, but occurs regardless of

20 whether the sampler is turned on or off. Exposure filters collect insects and dust from the local cliff-face directly below the sampler at the station, particularly during stormy conditions. This is a major concern for collecting marine-derived aerosol Fe particles in baseline air due to the very clean air (weak trace metal signal). As local aerosol debris may be found on filters deployed in high-volume aerosol samplers this type of sampler, in its current configuration, may not be appropriate for sampling marine aerosols representative of a broader region. For Southern Ocean studies, we recommend that (i) the use of microscope observations are a key tool for aiding in the identification of local contamination, (ii) land-based aerosol samplers are sealed during non-collection periods to prevent passive deposition, (iii) ship based aerosol samplers are also sealed when the sector of interest is not being sampled to prevent ship exhaust contamination, and (iv) acid-washed W41 filters are not suitable for studies of Al solubility in very low-level, clean air. Whilst this study shows significant exposure blanks in clean air conditions, this may not be a problem at sites influenced by air-masses containing higher aerosol $\mathrm{Fe}$ loadings. 
Atmos. Meas. Tech. Discuss., doi:10.5194/amt-2016-12, 2016

Manuscript under review for journal Atmos. Meas. Tech.

Published: 8 April 2016

(c) Author(s) 2016. CC-BY 3.0 License.

(c) (i)

\author{
Atmospheric \\ Measurement \\ Techniques \\ Discussions
}

\section{Data availability}

The dataset for blank filters is available through the Curtin University Research Data repository http://doi.org/10.4225/06/564AB348340D5.

\section{Acknowledgments}

5 This project was funded through Curtin University (Curtin Research Fellowship to R.E.), the University of Tasmania (B0019024 to A.R.B.), the Australian Research Council (FT130100037 to A.R.B.) and the Antarctic Climate and Ecosystems CRC. Access to HR-ICP-MS instrumentation at Curtin University was facilitated through ARC LIEF funding (LE130100029). V.H.L.W. would like to acknowledge the following scholarship support: Australian Postgraduate Award and Curtin Research Scholarship. CSIRO and the Australian Bureau of Meteorology in Australia are also thanked for their continuous support of CGBAPS, and we also thank Sam Clelend, Nigel Somerville and Jeremy Ward who made the collection of aerosol samples possible. Wind speed data for Cape Grim was sourced from the Australian Bureau of Meteorology. The authors acknowledge the use of equipment, scientific and technical assistance of the Curtin University Electron Microscope Facility, which has been partially funded by the University, State and Commonwealth Governments. We thank Phillip Boyd and Edward Butler for use of the high-volume aerosol sampler that was installed at CGBAPS. We 15 appreciate helpful discussion with Alex Baker on contamination issues with high-volume aerosol collection. We thank Alistair Williams, Scott Chambers and Sylvester Werczynski at ANSTO for their contribution to producing air mass back trajectories and plots. We thank and two anonymous reviewers who improved the paper. 
Atmos. Meas. Tech. Discuss., doi:10.5194/amt-2016-12, 2016

Manuscript under review for journal Atmos. Meas. Tech.

Published: 8 April 2016

(c) Author(s) 2016. CC-BY 3.0 License.

\author{
Atmospheric \\ Measurement \\ Techniques \\ Discussions
}

\title{
References
}

Aguilar-Islas, A. M., Wu, J., Rember, R., Johansen, A. M., and Shank, L. M.: Dissolution of aerosol-derived iron in seawater: Leach solution chemistry, aerosol type, and colloidal iron fraction, Marine Chemistry, 120, 25-33, 2010.

5 Annett, A. L., Lapi, S., Ruth, T. J., and Maldonado, M. T.: The Effects of $\mathrm{Cu}$ and Fe Availability on the Growth and Cu:C Ratios of Marine Diatoms, Limnology and Oceanography, 53, 2451-2461, 2008.

Ayers, G. P.: Influence of local soil dust on composition of aerosol samples at Cape Grim Baseline Atmospheric Program (Australia) 1997-98, 2001. 50-56, 2001.

Ayers, G. P. and Ivey, J. P.: Precipitation composition at Cape Grim, 1977-1985, Tellus B, 40B, 297-307, 1988.

10 Baker, A. R. and Croot, P. L.: Atmospheric and marine controls on aerosol iron solubility in seawater, Marine Chemistry, 120, 4-13, 2010.

Baker, A. R., Jickells, T. D., Witt, M., and Linge, K. L.: Trends in the solubility of iron, aluminium, manganese and phosphorus in aerosol collected over the Atlantic Ocean, Marine Chemistry, 98, 43-58, 2006.

Baseline: Baseline Atmospheric Program Australia 2009-2010. Edited by Derek. N, Krummel. P. B, Cleland. S. J. Australian

Bureau of Meteorology and CSIRO Marine and Atmospheric Research, 2014.

Bollhöfer, A., Chisholm, W., and Rosman, K. J. R.: Sampling aerosols for lead isotopes on a global scale, Analytica Chimica Acta, 390, 227-235, 1999.

Bollhöfer, A., Rosman, K. J. R., Dick, A. L., Chisholm, W., Burton, G. R., Loss, R. D., and Zahorowski, W.: Concentration, isotopic composition, and sources of lead in Southern Ocean air during 1999/2000, measured at the Cape Grim Baseline Air Pollution Station, Tasmania, Geochimica et Cosmochimica Acta, 69, 4747-4757, 2005.

Bowie, A. R., Lannuzel, D., Remenyi, T. A., Wagener, T., Lam, P. J., Boyd, P. W., Guieu, C., Townsend, A. T., and Trull, T. W.: Biogeochemical iron budgets of the Southern Ocean south of Australia: Decoupling of iron and nutrient cycles in the subantarctic zone by the summertime supply, Global Biogeochem. Cycles, 23, GB4034, 2009.

Boyd, P. W., Jickells, T., Law, C. S., Blain, S., Boyle, E. A., Buesseler, K. O., Coale, K. H., Cullen, J. J., de Baar, H. J. W., 25 Follows, M., Harvey, M., Lancelot, C., Levasseur, M., Owens, N. P. J., Pollard, R., Rivkin, R. B., Sarmiento, J., Schoemann, V., Smetacek, V., Takeda, S., Tsuda, A., Turner, S., and Watson, A. J.: Mesoscale Iron Enrichment Experiments 1993-2005: Synthesis and Future Directions, Science, 315, 612-617, 2007.

Chance, R., Jickells, T. D., and Baker, A. R.: Atmospheric trace metal concentrations, solubility and deposition fluxes in remote marine air over the south-east Atlantic, Marine Chemistry, 2015. 2015.

30 Chow, J. C.: Measurement methods to determine compliance with ambient air quality standards for suspended particles, Journal of the Air \& Waste Management Association, 45, 320-382, 1995.

Cohen, D. D., Garton, D., and Stelcer, E.: Multi-elemental methods for fine particle source apportionment at the global baseline station at Cape Grim, Tasmania, Nuclear Instruments and Methods in Physics Research Section B: Beam Interactions with Materials and Atoms, 161, 775-779, 2000.

35 Cohen, D. D. and Stelcer, E.: Fine particle sampling at Cape Grim, 2009-2010 Baseline report, 2014. 75, 2014. 
Atmos. Meas. Tech. Discuss., doi:10.5194/amt-2016-12, 2016

Manuscript under review for journal Atmos. Meas. Tech.

Published: 8 April 2016

(c) Author(s) 2016. CC-BY 3.0 License.

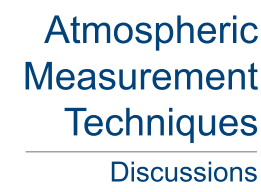

(c)

Cutter, G., Andersson, P., Codispoti, L., Croot, P., Francois, R., Lohan, M., Obata, H., and Rutgers vd Loeff, M.: Sampling and sample-handling protocols for GEOTRACES Cruises, 2010. 2010.

Draxler, R. R. and Rolph, G. D.: Hybrid Single-Particle Lagrangian Integrated Trajectory (HYSPLIT), model, http://www.arl.noaa.gov/ready/hysplit4.html, 2003. 2003.

5 Duce, R. A., Liss, P. S., Merrill, J. T., Atlas, E. L., Buat-Menard, P., Hicks, B. B., Miller, J. M., Prospero, J. M., Arimoto, R., Church, T. M., Ellis, W., Galloway, J. N., Hansen, L., Jickells, T. D., Knap, A. H., Reinhardt, K. H., Schneider, B., Soudine, A., Tokos, J. J., Tsunogai, S., Wollast, R., and Zhou, M.: The atmospheric input of trace species to the world ocean, Global Biogeochem. Cycles, 5, 193-259, 1991.

Edwards, R.: Iron in modern and ancient East Antarctic snow: implications for phytoplankton production in the Southern Ocean, PhD thesis, University of Tasmania, Hobart, 1999. 1999.

Fishwick, M. P., Sedwick, P. N., Lohan, M. C., Worsfold, P. J., Buck, K. N., Church, T. M., and Ussher, S. J.: The impact of changing surface ocean conditions on the dissolution of aerosol iron, Global Biogeochemical Cycles, doi:

10.1002/2014GB004921, 2014. 2014GB004921, 2014.

Fomba, K., Müller, K., Pinxteren, D. v., and Herrmann, H.: Aerosol size-resolved trace metal composition in remote

15 northern tropical Atlantic marine environment: case study Cape Verde Islands, Atmospheric Chemistry and Physics Discussions, 12, 29535-29569, 2012.

Gao, Y., Xu, G., Zhan, J., Zhang, J., Li, W., Lin, Q., Chen, L., and Lin, H.: Spatial and particle size distributions of atmospheric dissolvable iron in aerosols and its input to the Southern Ocean and coastal East Antarctica, Journal of Geophysical Research: Atmospheres, 118, 12,634-612,648, 2013.

20 Heimburger, A., Losno, R., and Triquet, S.: Solubility of iron and other trace elements in rainwater collected on the Kerguelen Islands (South Indian Ocean), Biogeosciences, 10, 2013a.

Heimburger, A., Losno, R., Triquet, S., Dulac, F., and Mahowald, N.: Direct measurements of atmospheric iron, cobalt, and aluminum-derived dust deposition at Kerguelen Islands, Global Biogeochemical Cycles, 26, 2012.

Heimburger, A., Losno, R., Triquet, S., and Nguyen, E.: Atmospheric deposition fluxes of 26 elements over the Southern

Indian Ocean: Time series on Kerguelen and Crozet Islands, Global Biogeochemical Cycles, 27, 440-449, 2013b.

Kadko, D., Landing, W. M., and Shelley, R. U.: A novel tracer technique to quantify the atmospheric flux of trace elements to remote ocean regions, Journal of Geophysical Research: Oceans, 2015. 2015.

Keeling, R. F., Piper, S. C., and Heimann, M.: Global and hemispheric CO2 sinks deduced from changes in atmospheric O2 concentration, Nature, 381, 218-221, 1996.

30 Keywood, M.: An evaluation of PM10 and PM2. 5 size selective inlet performance using ambient aerosol, Aerosol Science \& Technology, 30, 401-407, 1999.

Keywood, M. D.: Aerosol composition at Cape Grim : an evaluation of PM10 sampling program and baseline event switches., Baseline Atmospheric Program Australia 2005-2006. 2005-2006 ed. J. M. Cainey, N. Derek, and P. B. Krummel (editors). Melbourne: Australian Bureau of Meteorology and CSIRO Marine and Atmospheric Research, 2007. 31-36, 2007.

35 Lambert, F., Tagliabue, A., Shaffer, G., Lamy, F., Winckler, G., Farias, L., Gallardo, L., and De Pol-Holz, R.: Dust fluxes and iron fertilization in Holocene and Last Glacial Maximum climates, Geophysical Research Letters, doi:

10.1002/2015GL064250, 2015. n/a-n/a, 2015. 
Atmos. Meas. Tech. Discuss., doi:10.5194/amt-2016-12, 2016

Manuscript under review for journal Atmos. Meas. Tech.

Published: 8 April 2016

(c) Author(s) 2016. CC-BY 3.0 License.

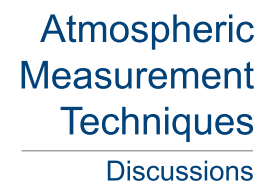

$\begin{array}{r}\text { Atmospheric } \\ \text { Measurement } \\ \text { Techniques } \\ \hline \text { Discussions }\end{array}$

\section{(c) (i)}

Li-Jones, X. and Prospero, J.: Variations in the size distribution of non-sea-salt sulfate aerosol in the marine boundary layer at Barbados: Impact of African dust, Journal of Geophysical Research: Atmospheres (1984-2012), 103, 16073-16084, 1998.

Martin, J. H.: Glacial-interglacial CO2 change: the iron hypothesis, Paleoceanography, 5, 1-11, 1990.

Martínez-García, A., Sigman, D. M., Ren, H., Anderson, R. F., Straub, M., Hodell, D. A., Jaccard, S. L., Eglinton, T. I., and

Middag, R., De Baar, H., Laan, P., Cai, P., and Van Ooijen, J.: Dissolved manganese in the Atlantic sector of the Southern Ocean, Deep Sea Research Part II: Topical Studies in Oceanography, 58, 2661-2677, 2011.

Morel, F. and Price, N.: The biogeochemical cycles of trace metals in the oceans, Science, 300, 944-947, 2003.

Morel, F. M., Hudson, R. J., and Price, N. M.: Limitation of productivity by trace metals in the sea, Limnology and Oceanography, 36, 1742-1755, 1991.

Morton, P. L., Landing, W. M., Hsu, S.-C., Milne, A., Aguilar-Islas, A. M., Baker, A. R., Bowie, A. R., Buck, C. S., Gao, Y., and Gichuki, S.: Methods for the sampling and analysis of marine aerosols: results from the 2008 GEOTRACES aerosol intercalibration experiment, Limnology and Oceanography: Methods, 11, 62-78, 2013.

Price, N. and Morel, F.: Colimitation of phytoplankton growth by nickel and nitrogen, LIMNOLOGY, 1991. 1991.

15 Prospero, J. M.: The atmospheric transport of particles to the ocean, in Particle Flux in the Ocean, John Wiley, Hoboken, N. J, 1996.

Saito, M. A., Moppett, J., Chisholm, S. W., and Waterbury, J. B.: Cobalt limitation and uptake in Prochlorococcus, Limnology and Oceanography, 47, 1629-1636, 2002.

Selleck, P. W., Keywood, M. D., Ward, J. P., Gillett, R. W., and Boast, K.: Aerosol samplers and chemical composition, 2009-2010 Baseline report, 76-79., 2014. 2014.

Sholkovitz, E. R., Sedwick, P. N., Church, T. M., Baker, A. R., and Powell, C. F.: Fractional solubility of aerosol iron: Synthesis of a global-scale data set, Geochimica et cosmochimica acta, 89, 173-189, 2012.

Stafford, R. G. and Ettinger, H. J.: Filter efficiency as a function of particle size and velocity, Atmospheric Environment (1967), 6, 353-362, 1972.

25 Taylor, S. R. and McLennan, S. M.: The continental crust: Its composition and evolution, 1985.

Vallelonga, P., Van de Velde, K., Candelone, J. P., Ly, C., Rosman, K. J. R., Boutron, C. F., Morgan, V. I., and Mackey, D. $\mathrm{J} .:$ Recent advances in measurement of $\mathrm{Pb}$ isotopes in polar ice and snow at sub-picogram per gram concentrations using thermal ionisation mass spectrometry, Analytica Chimica Acta, 453, 1-12, 2002.

Wagener, T., Guieu, C., Losno, R., Bonnet, S., and Mahowald, N.: Revisiting atmospheric dust export to the Southern Hemisphere ocean: Biogeochemical implications, Global Biogeochem. Cycles, 22, GB2006, 2008.

Wedepohl, K. H.: The composition of the continental crust, Geochimica et Cosmochimica Acta, 59, 1217-1232, 1995.

Winton, V. H. L., Bowie, A. R., Edwards, R., Keywood, M., Townsend, A. T., van der Merwe, P., and Bollhöfer, A.: Fractional iron solubility of atmospheric iron inputs to the Southern Ocean, Marine Chemistry, 177, Part 1, 20-32, 2015. 
Atmos. Meas. Tech. Discuss., doi:10.5194/amt-2016-12, 2016

Manuscript under review for journal Atmos. Meas. Tech.

Published: 8 April 2016

(c) Author(s) 2016. CC-BY 3.0 License.

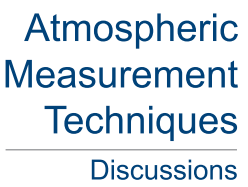

(c) (1)

Table 1: Filter blank and aerosol sampling duration and volume.

\begin{tabular}{cccccc}
\hline & & & & Total sampling \\
time & $\begin{array}{c}\text { Total sampling } \\
\text { volume } \mathbf{( m}^{\mathbf{3}} \mathbf{)}\end{array}$ \\
\hline Procedural blank & TSP & $8 / 08 / 2013$ & $8 / 08 / 2013$ & 5 minutes & 0 \\
Exposure blank & PM10 & $8 / 11 / 2013$ & $10 / 12 / 2013$ & 1 month & 0 \\
CG13TM01 & TSP & $12 / 06 / 2013$ & $16 / 07 / 2013$ & 814.7 hours & 59473 \\
CG13TM08 & PM10 & $28 / 01 / 2014$ & $25 / 02 / 2014$ & 143.3 hours & 10461 \\
\hline
\end{tabular}


Atmos. Meas. Tech. Discuss., doi:10.5194/amt-2016-12, 2016

Manuscript under review for journal Atmos. Meas. Tech.

Published: 8 April 2016

(c) Author(s) 2016. CC-BY 3.0 License.

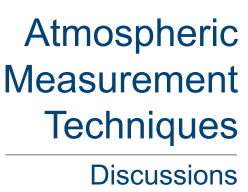

(c) (1)

Table 2: Average total trace metal concentration in filtrates. Data for blank filters are corrected for the digestion blank (Savillex ${ }^{\circledR}$ beaker blank). Errors are the standard deviation of the three sub-samples. DL: Detection limit. 
Atmos. Meas. Tech. Discuss., doi:10.5194/amt-2016-12, 2016

Manuscript under review for journal Atmos. Meas. Tech.

Published: 8 April 2016

(c) Author(s) 2016. CC-BY 3.0 License.

(c) (1)
Atmospheric

Measurement

Techniques

Discussions
Al

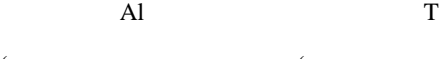

(ng $\quad$ (ng $\quad$ (ng $\quad$ (ng $\quad$ (ng $\quad$ (pg

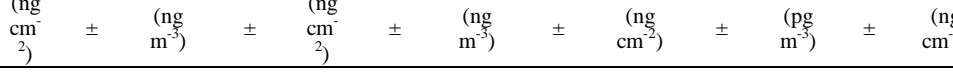

Instrumental

blank $(\mathrm{n}=10)$

$0.01 \quad 0.004<0.001 \quad<0.001=0.001$

$<0.001$

$<0.001<0.001$

$<0.001<0.001$

$0.001<0.001<0.001$

(

blank $(n=3)$

(1)

$$
\text { 政 }
$$

$$
\text { fil }
$$

Untreated Aci

t

$$
\text { Proce }
$$

\begin{tabular}{|c|c|c|c|c|c|c|c|c|c|c|c|c|c|c|c|c|c|c|c|c|c|c|c|c|}
\hline $\begin{array}{c}\text { Exposure } \\
\text { blank }(n=3)\end{array}$ & 250 & 20 & 9.8 & 0.9 & 48 & 5 & 1.9 & 0.2 & 0.61 & 0.05 & 24 & 2 & 3.3 & 0.8 & 0.1 & 0.03 & 260 & 30 & 10 & 1 & 0.08 & 0.03 & 3 & 1 \\
\hline
\end{tabular}$$
\mathrm{Pr}
$$

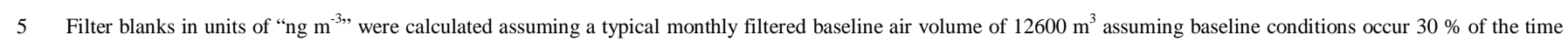

6 (Keywood, 2007). 
Atmos. Meas. Tech. Discuss., doi:10.5194/amt-2016-12, 2016

Manuscript under review for journal Atmos. Meas. Tech.

Published: 8 April 2016

(c) Author(s) 2016. CC-BY 3.0 License.

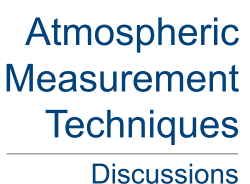

(c) (i)

1 Table 3: Average trace metal soluble concentration in filtrates. Data for blank filters are corrected for the 2 instrumental blank. Errors are the standard deviation of the three sub-samples. 
Atmos. Meas. Tech. Discuss., doi:10.5194/amt-2016-12, 2016

Manuscript under review for journal Atmos. Meas. Tech.

Published: 8 April 2016

(c) Author(s) 2016. CC-BY 3.0 License.
Atmospheric

Measurement

Techniques

Discussions

(c) (i)

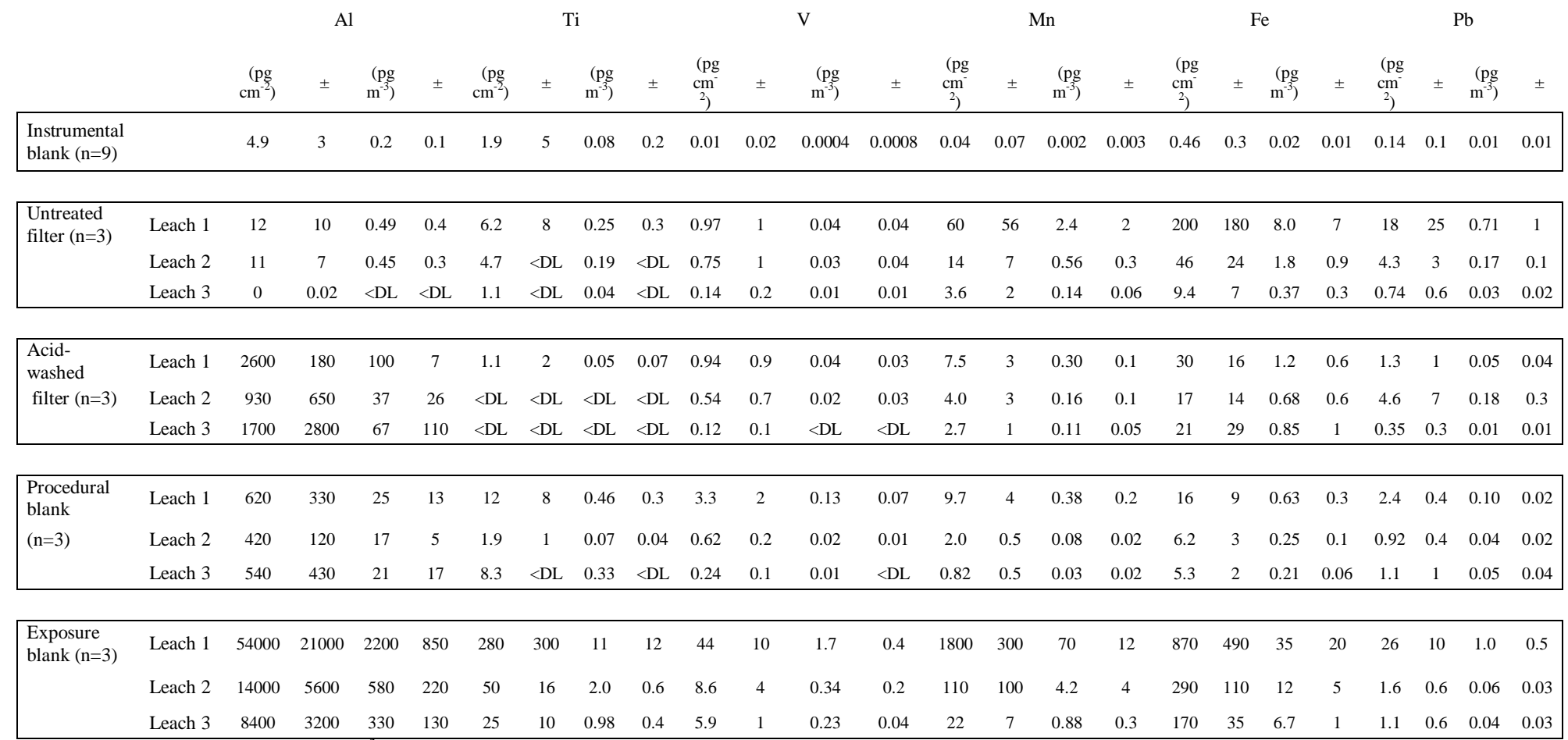

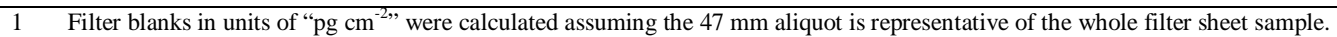

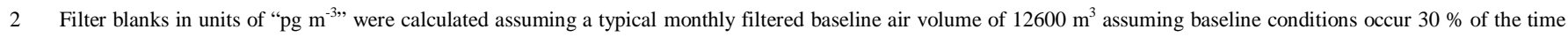

3 (Keywood, 2007). 
Atmos. Meas. Tech. Discuss., doi:10.5194/amt-2016-12, 2016

Manuscript under review for journal Atmos. Meas. Tech.

Published: 8 April 2016

(c) Author(s) 2016. CC-BY 3.0 License.

Table 4: Blank iron contamination budget.

\begin{tabular}{lcccc}
\hline & $\begin{array}{c}\text { Total Fe } \\
\left(\mathrm{ng} \mathrm{cm}^{-2}\right)\end{array}$ & $\begin{array}{c}\text { Soluble Fe } \\
\left(\mathrm{ng} \mathrm{cm}^{-2}\right)\end{array}$ & $\begin{array}{c}\text { Fe blank } \\
\text { contribution (ng } \\
\left.\mathrm{cm}^{-2}\right)\end{array}$ & $\begin{array}{c}\text { Fe blank } \\
\text { contribution (\%) }\end{array}$ \\
\hline Digestion & ${ }^{1} 0.2$ & 0.2 & 0.1 \\
Acid & ${ }^{2} 0.0006$ & ${ }^{3} 0.00004$ & 0.0007 & $<0.001$ \\
Instrument & ${ }^{4} 0.0004$ & ${ }^{5} 0.0005$ & 0.0009 & $<0.001$ \\
W41 filter & ${ }^{6} 6.6$ & ${ }^{7} 0.2$ & 6.8 & 3 \\
Sampling procedure & ${ }^{8}$ negligible & ${ }^{9}$ negligible & 0 & $<0.001$ \\
Month exposure at field site & ${ }^{10} 254$ & 11 1 & 255 & 98 \\
\hline Total & 261 & 1 & 262 &
\end{tabular}

2 Method of determination: ${ }^{1}$ Digested Savlliex ${ }^{\circledR}$ blank beaker with $0.5 \mathrm{~mL}$ of $\mathrm{HNO}_{3}$ (Baseline Seastar ${ }^{\circledR}$ ) and 0.25

$3 \mathrm{~mL} \mathrm{HF}$ (Baseline Seastar ${ }^{\circledR}$ ) (acid and instrument blank subtracted); ${ }^{2}$ Assuming certified maximum specification

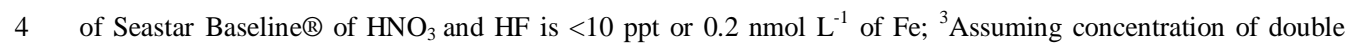

5 distilled in-house $\mathrm{HCl}$ from Seastar ${ }^{\circledR}$ IQ grade quality (Choice Analytical Pty Ltd, Australia) is $<10$ ppt or 0.2

$6 \mathrm{nmol} \mathrm{L}{ }^{-1}$ of Fe; ${ }^{4}$ Vials filled with ultra-pure water acidified to $3 \%$ or $0.5 \mathrm{~mol} \mathrm{~L}^{-1} \mathrm{HNO}_{3}$; ${ }^{5}$ Vials filled with ultra-

7 pure water acidified to $1 \%$ or $0.12 \mathrm{~mol} \mathrm{~L}^{-1} \mathrm{HCl}$; ${ }^{6}$ Total digestion of untreated filter (digestion, instrument and

8 acid-washed filter blank subtracted); ${ }^{7}$ Water soluble leach of untreated filter (instrument and acid-washed filter

9 blank subtracted); ${ }^{8}$ Total digestion of procedural blank filter (digestion, instrument and acid-washed filter blank

10 subtracted); ${ }^{9}$ Water soluble leach of procedural blank filter (instrument and acid-washed filter blank subtracted);

$11{ }^{10}$ Total digestion of exposure blank filter (digestion, instrument and procedural blank filter subtracted); ${ }^{11}$ Water

12 soluble leach of exposure blank filter (instrument and procedural blank filter subtracted). Negligible is defined

13 as $<0.01 \mathrm{pg} \mathrm{cm}^{3}$ of Fe. 
Atmos. Meas. Tech. Discuss., doi:10.5194/amt-2016-12, 2016

Manuscript under review for journal Atmos. Meas. Tech.

Published: 8 April 2016

(c) Author(s) 2016. CC-BY 3.0 License.

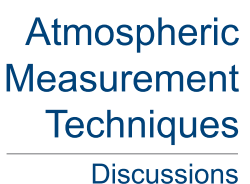

(c) (1)

1 Table 5: Enrichment factors of trace metals relative to Al measured in exposure and procedural blank filters. The 2 composition of the upper continent crust is based from Wedepohl (1995).

\begin{tabular}{cccccc}
\hline & $\mathrm{Ti}$ & $\mathrm{Fe}$ & $\mathrm{Mn}$ & $\mathrm{V}$ & $\mathrm{Pb}$ \\
\hline Exposure blank & 4.8 & 2.7 & 2.0 & 3.6 & 1.5 \\
\hline
\end{tabular}


Atmos. Meas. Tech. Discuss., doi:10.5194/amt-2016-12, 2016

Manuscript under review for journal Atmos. Meas. Tech.

Published: 8 April 2016

(c) Author(s) 2016. CC-BY 3.0 License.

\section{Atmospheric \\ Measurement \\ Techniques \\ Discussions}

cC) (i)
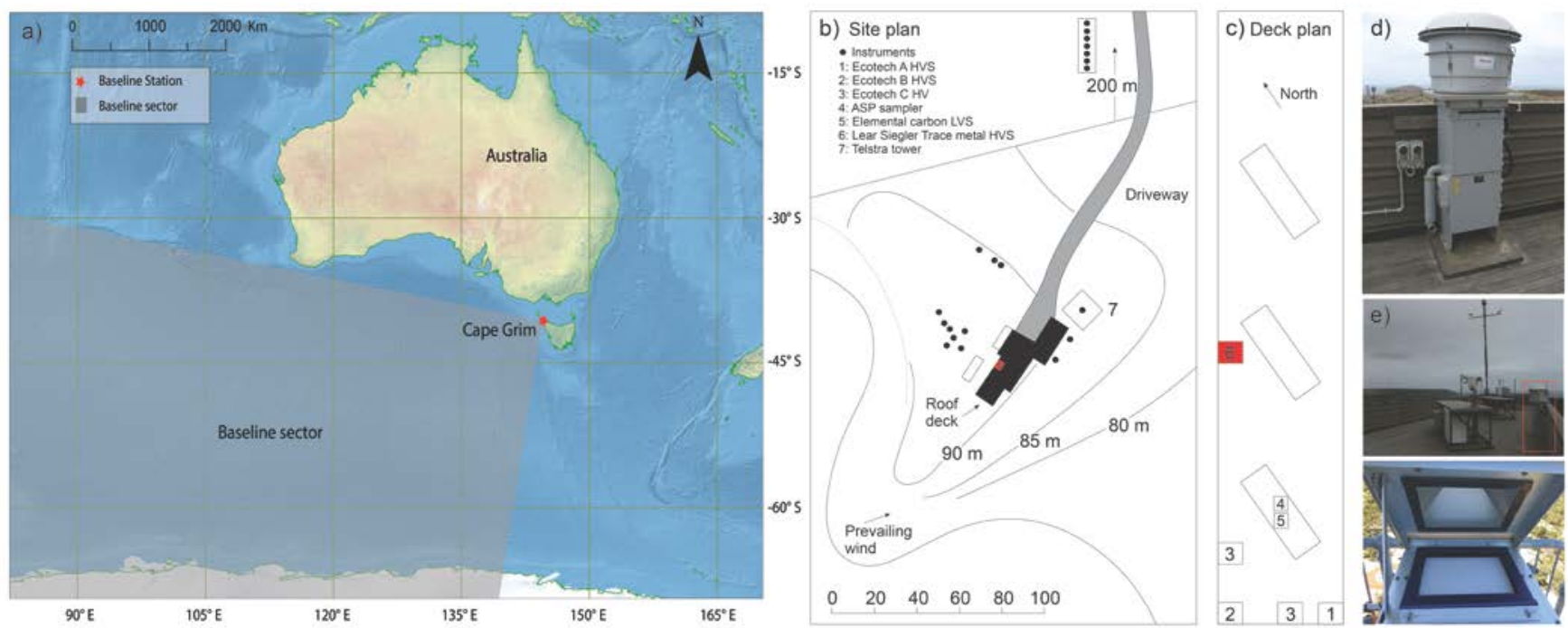

Fig. 1: a) Location of the CGBAPS and the high-volume aerosol sampler installed on the roof deck. Baseline conditions occur when the wind direction is between $190^{\circ}$ and $280^{\circ}$ and the total aerosol particle counts are below a threshold concentration based on the

590 percentile of hourly medians for the previous five years. b) CGBAPS site plan, b) roof deck plan, d-e) LSA high-volume aerosol sample attached with PM10 size selective inlet (photo credit: Jeremy Ward), f) filter inside the sampler. Panels b) and c) modified from Baseline Report 2009-2010 (Baseline, 2014). 
Atmos. Meas. Tech. Discuss., doi:10.5194/amt-2016-12, 2016

Manuscript under review for journal Atmos. Meas. Tech.

Published: 8 April 2016

(c) Author(s) 2016. CC-BY 3.0 License.

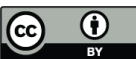

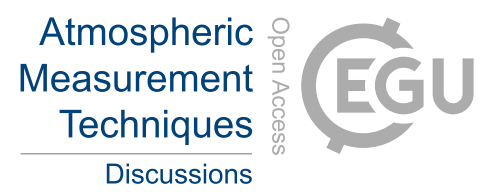

Discussions
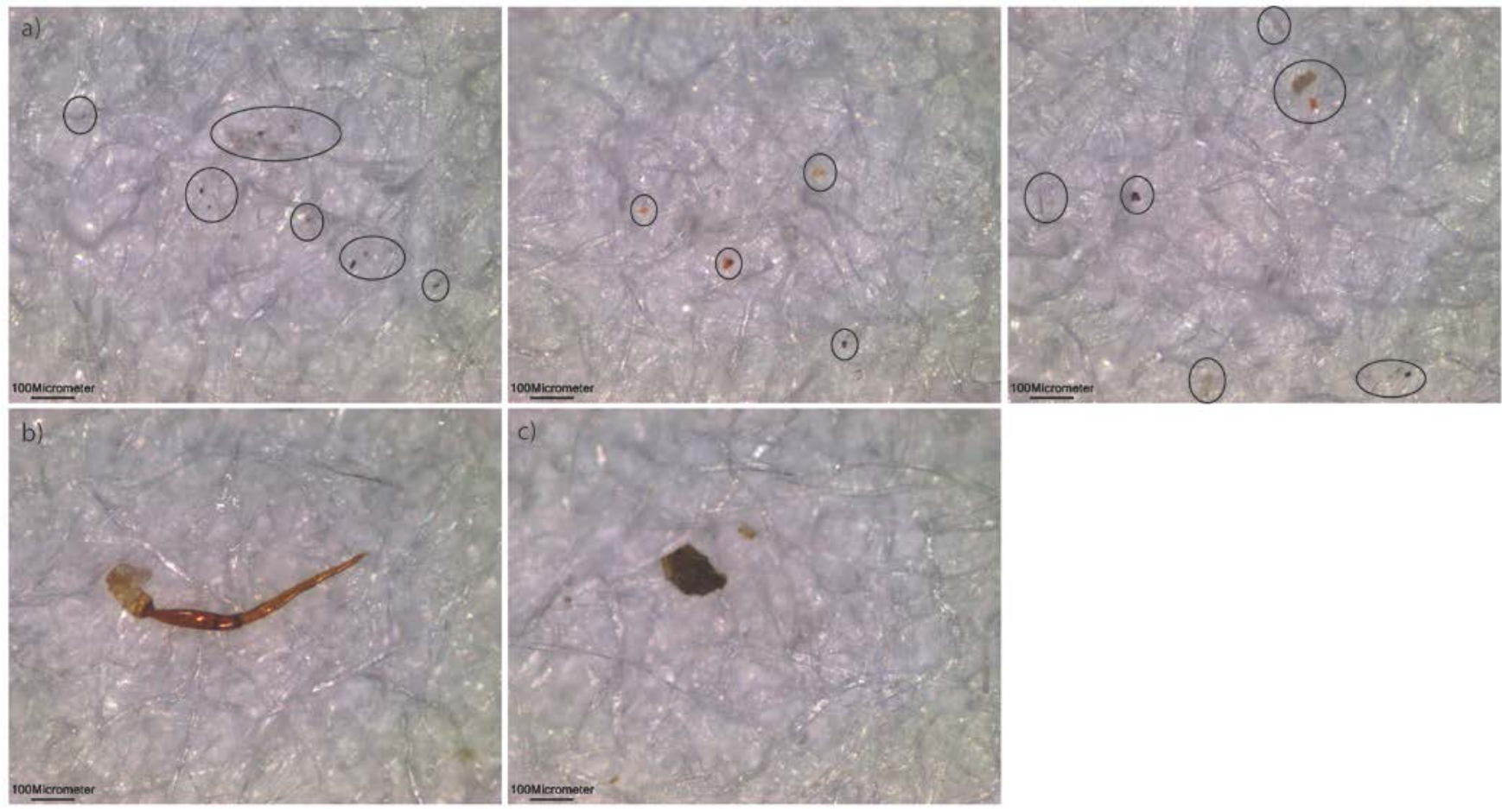

Fig. 2: Optical microscopy images of contaminated exposure blanks showing examples of particles on the filter. a) three examples of windblown particles, b) insect leg, c) large soil particle. Areas of interest are circled. 
Atmos. Meas. Tech. Discuss., doi:10.5194/amt-2016-12, 2016

Manuscript under review for journal Atmos. Meas. Tech.

Published: 8 April 2016

(c) Author(s) 2016. CC-BY 3.0 License.

(c) (i)
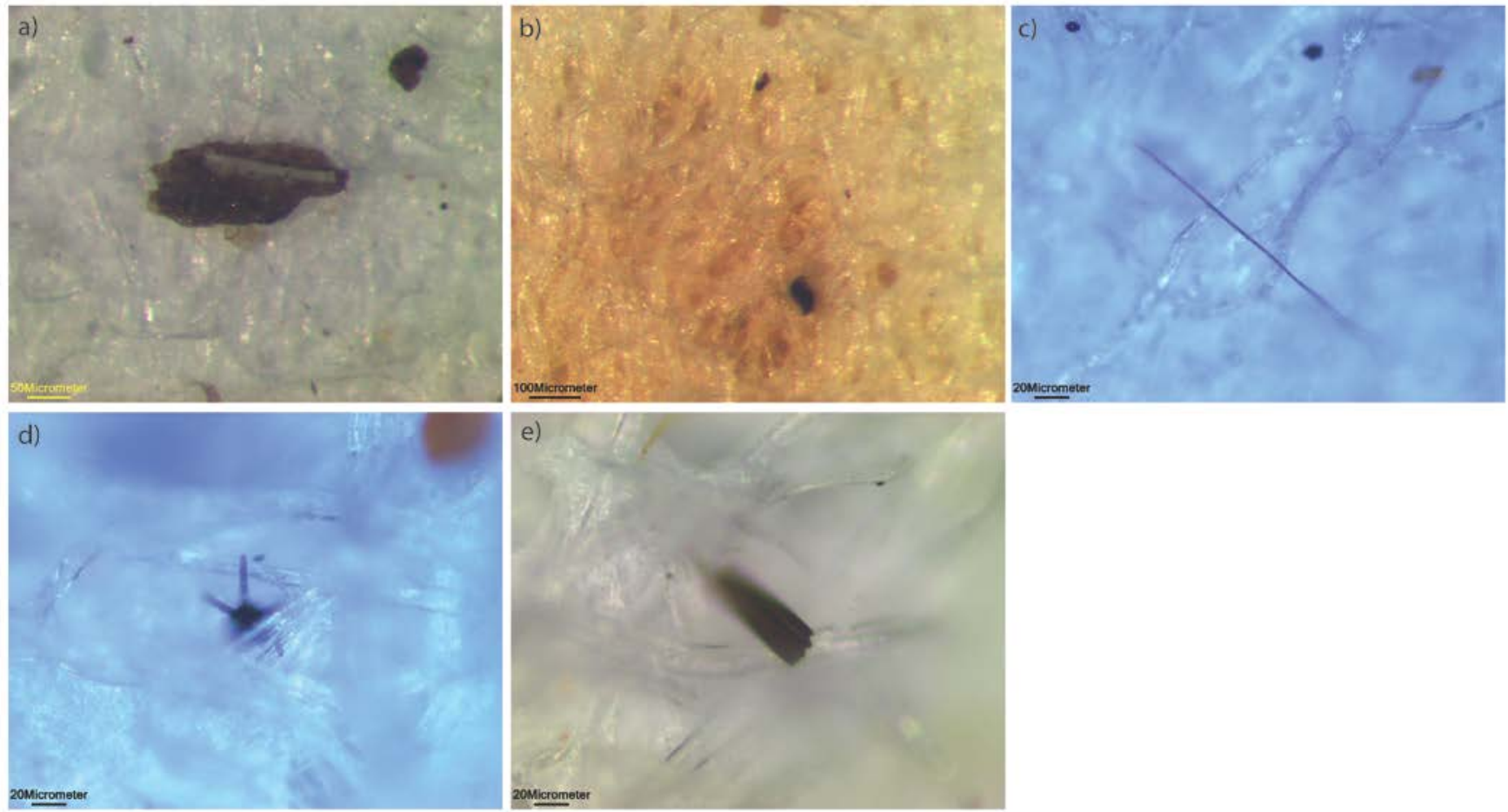

Atmospheric Measurement Techniques

Discussions 
Atmos. Meas. Tech. Discuss., doi:10.5194/amt-2016-12, 2016

Manuscript under review for journal Atmos. Meas. Tech.

Published: 8 April 2016

(c) Author(s) 2016. CC-BY 3.0 License.

\section{(c) (i)}
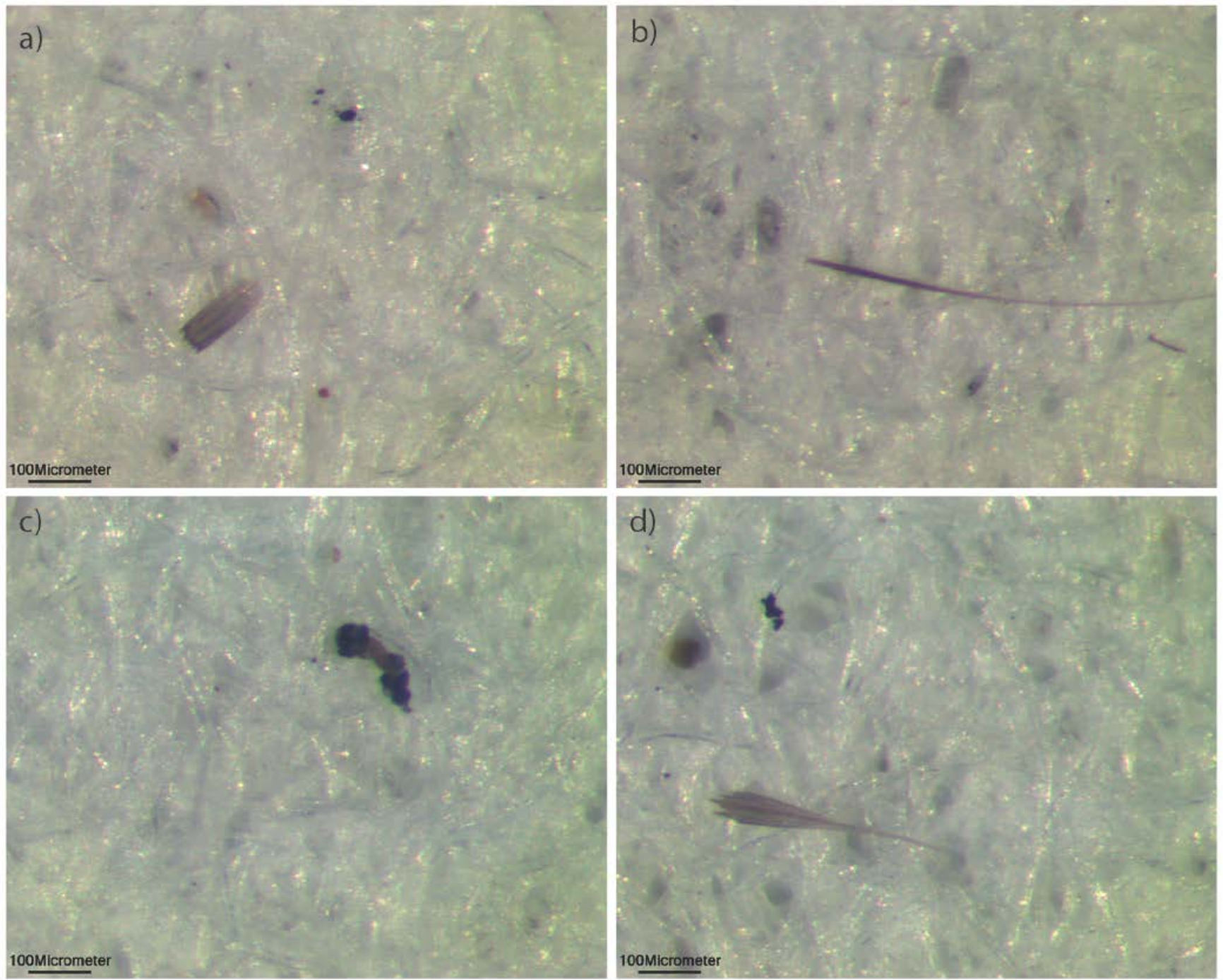

Fig. 4: Optical microscopy images of examples of particles collected on PM10 filter (CG13TM08). a) moth spare, b) grass, c-d) large windblown particles. 
Atmos. Meas. Tech. Discuss., doi:10.5194/amt-2016-12, 2016

Manuscript under review for journal Atmos. Meas. Tech.

Published: 8 April 2016

(c) Author(s) 2016. CC-BY 3.0 License.

\section{(c) (i)}

\section{Atmospheric \\ Measurement \\ Techniques \\ Discussions}
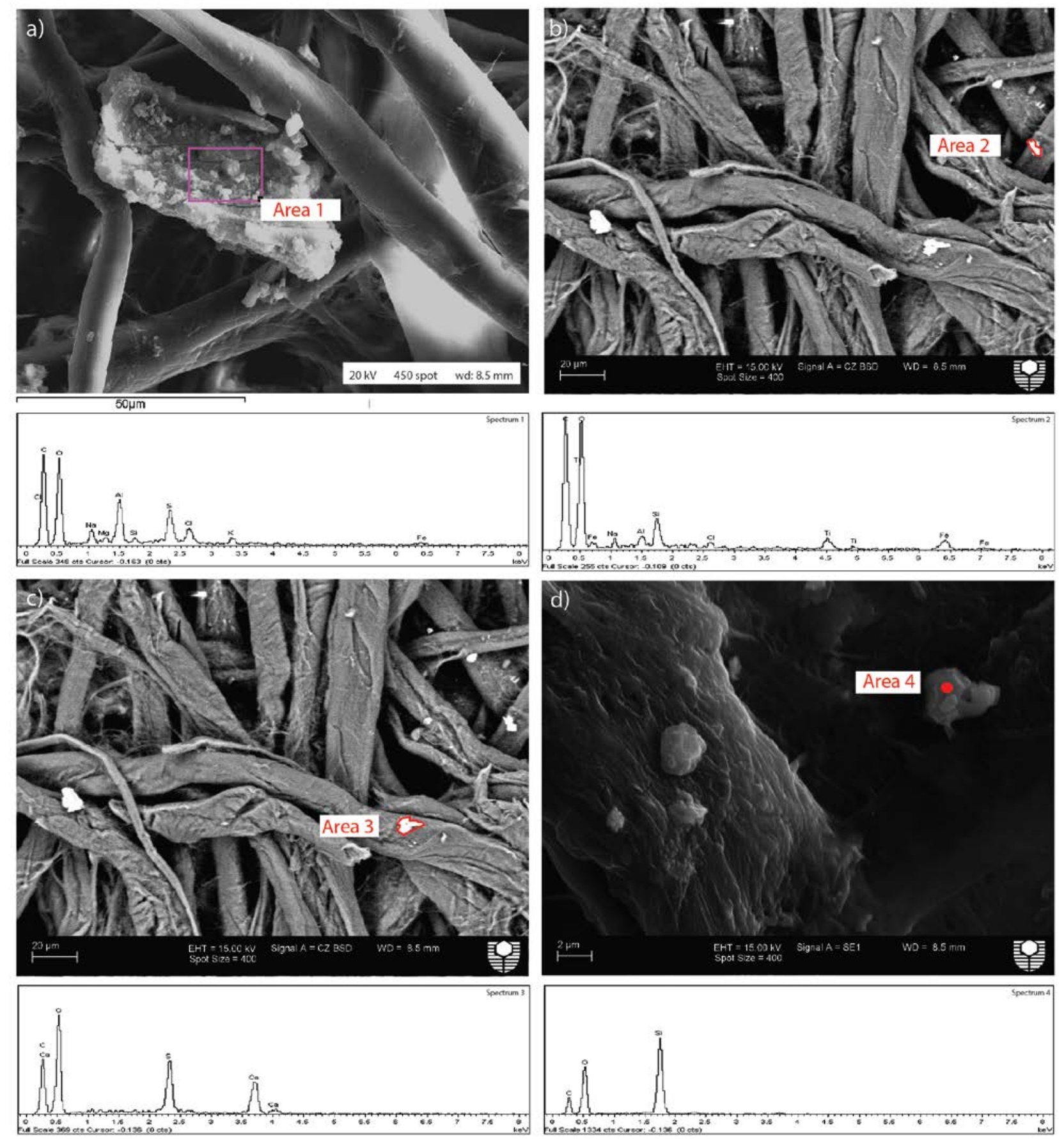

Fig. 5: Scanning Electron Microscope images and spectra of particles on a PM10 filter (CG13TM08). a) salt particle (sodium chloride) (detector: SE, instrument: EVO), b) soil (detector: BSD, instrument: EVO), c) calcium carbonate (detector: BSD, 5 instrument: EVO), d) marine silica (detector: SE, instrument: EVO). 
Atmos. Meas. Tech. Discuss., doi:10.5194/amt-2016-12, 2016

Manuscript under review for journal Atmos. Meas. Tech.

Published: 8 April 2016

(c) Author(s) 2016. CC-BY 3.0 License.

\section{Atmospheric Measurement Techniques \\ Discussions

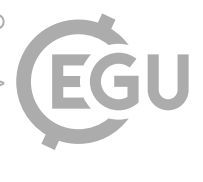

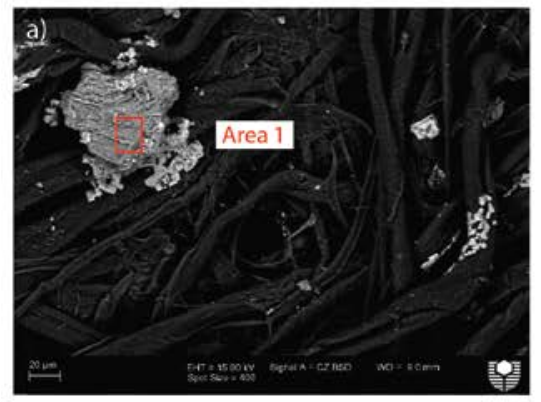
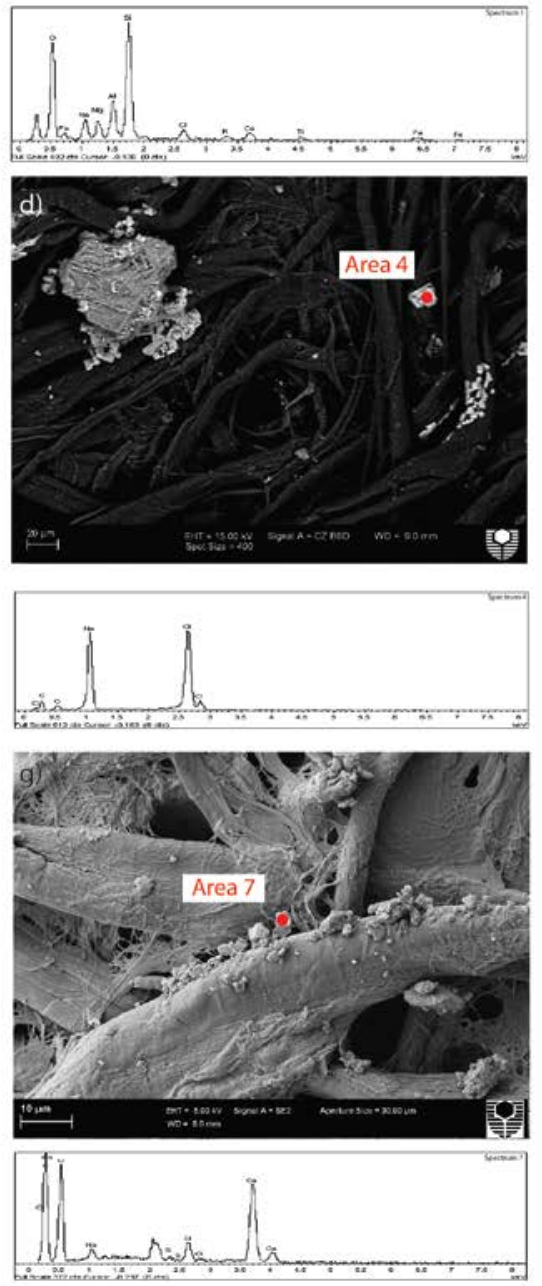
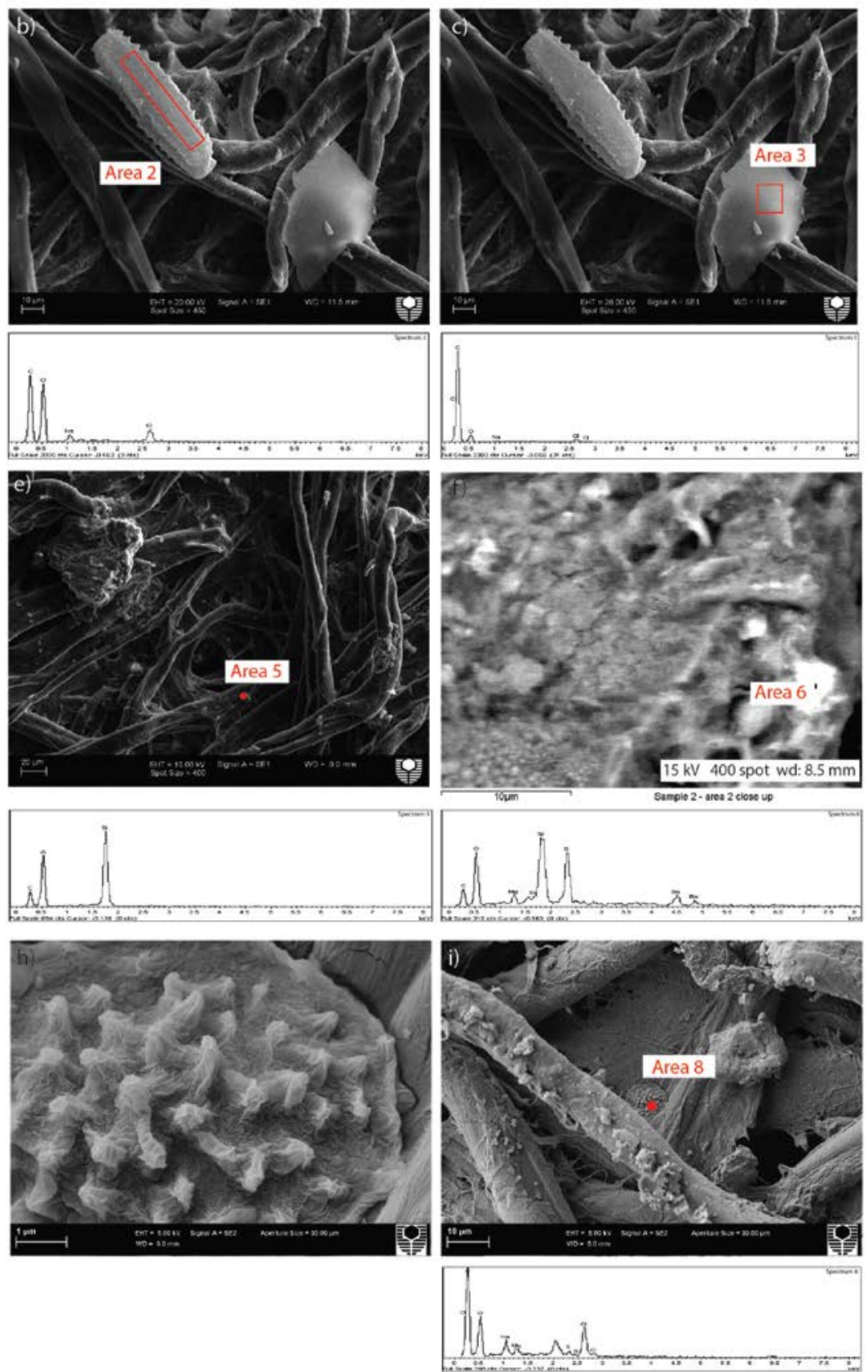

Fig. 6: Scanning Electron Microscope images and spectra of particles on a TSP filter (CG13TM01). a) mineral dust (Fe, Mg, Al, Si, Ti, K) (detector: BSD, instrument: EVO), b) organic material (detector: BC, instrument: NEO), c) organic carbonaceous particle

5 (detector: BC, instrument: NEO), d) cubical salt (sodium chloride) (detector: BSD, instrument: EVO), e) silica sand (detector: BC, instrument: EVO), f) marine aerosol (detector: BSD, instrument: EVO), g) marine aerosol (Mg, Sr, Ba, Cl, Ca, $\mathrm{Na}$ ) (detector: BC, instrument: EVO), h-i) spore (detector: BC, instrument: EVO). 
Atmos. Meas. Tech. Discuss., doi:10.5194/amt-2016-12, 2016

Manuscript under review for journal Atmos. Meas. Tech.

Published: 8 April 2016

(C) Author(s) 2016. CC-BY 3.0 License.

(c) (i)

a)

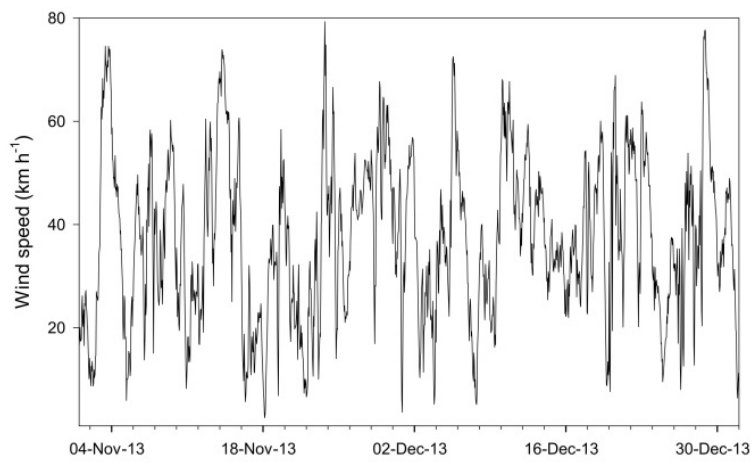

b)

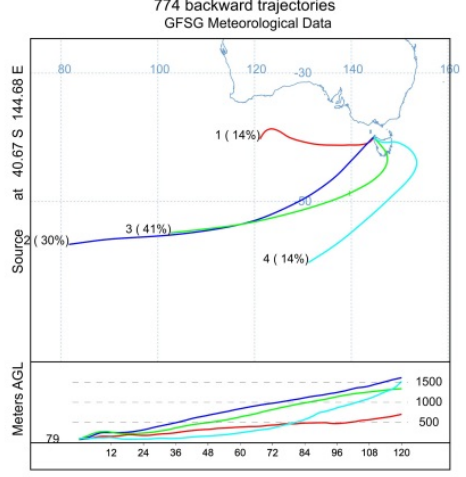

Atmospheric Measurement Techniques Discussions

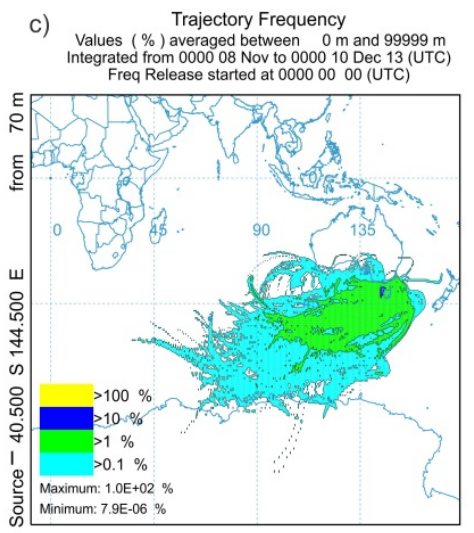

Fig. 7: Wind speed and fetch area of air masses associated with the whole duration of one month long exposure blank from 8 November to 10 December 2013. a) Time series of hourly wind speed (times are in the GMT+10 time zone; data sourced from the 5 Australian Bureau of Meteorology), b) Cluster means of 5 day hourly air mass back trajectories. 